\title{
A probabilistic model for fracture events of Petermann ice islands under the influence of atmospheric and oceanic conditions
}

\author{
Reza Zeinali-Torbati ${ }^{1}$, Ian D. Turnbull ${ }^{2}$, Rocky S. Taylor ${ }^{1}$, Derek Mueller ${ }^{3}$ \\ ${ }^{1}$ Faculty of Engineering and Applied Science, Memorial University of Newfoundland, St. John's, NL A1B 3X5, Canada \\ $5 \quad{ }^{2}$ Ice Engineering, C-CORE, St. John's, NL A1B 3X5, Canada \\ ${ }^{3}$ Department of Geography and Environmental Studies, Carleton University, Ottawa, ON K1S 5B6, Canada
}

Correspondence to: Reza Zeinali-Torbati (rzt313@mun.ca)

Abstract. Four calving events of Petermann Glacier happened in 2008, 2010, 2011, and 2012, which resulted in the drift and

10 deterioration of numerous ice islands, some reaching as far as offshore Newfoundland. The presence of these ice islands in the eastern Canadian Arctic increases the risk of interaction with offshore operations and shipping activities. This study used the recently developed Canadian Ice Island Drift, Deterioration and Detection database to investigate the fracture events that these ice islands experienced, and presented a probabilistic model for the conditional occurrence of such events by analyzing the atmospheric and oceanic conditions that drive the causes behind the ice island fracture events. Variables representing the

15 atmospheric and oceanic conditions that the ice islands were subjected to were extracted from reanalysis datasets and then interpolated to evaluate their distributions for both fracture and non-fracture events. The probability of fracture event occurrence for different combinations of input variable conditions were quantified using Bayes theorem. Out of the seven variables analyzed in this study, water temperature and ocean current speed were identified as the most and least important contributors, respectively, to the fracture events of the Petermann ice islands. It was also revealed that the ice island fracture probability increased to $75 \%$ as the ice islands encountered extreme (very high) atmospheric and oceanic conditions. A validation scheme was presented using cross-validation approach and Pareto principle, and an average error of 13-39\% was reported in the fracture probability estimations. The presented probabilistic model has a predictive capability for future fracture events of ice islands and could be of particular interest to offshore and marine activities in the eastern Canadian Arctic. Future research, however, is necessary for model training and testing to further validate the presented ice island fracture model.

\section{Introduction}

With the advancement of offshore operations and shipping activities into the harsh environment in the eastern Canadian waters, these activities are being subjected to greater risks from glacial ice features (Saper, 2011). The shipping and resource extraction industries in this region, therefore, require a better understanding of the dynamics and physical properties of these

30 ice features to be able to devise appropriate ice management strategies for safe operations. Specifically, a more solid understanding of the drift and deterioration characteristics of icebergs and ice islands (large tabular icebergs) is needed for 
https://doi.org/10.5194/tc-2021-83

Preprint. Discussion started: 18 May 2021

(c) Author(s) 2021. CC BY 4.0 License.

\section{(c) (i)}

risk management strategies. However, due to the occasional presence of ice islands in regions with lower latitudes such as offshore Newfoundland and Labrador (Johannessen et al., 2011), there has been limited research on the dynamics of ice islands, when compared to the research concerning annual presence of smaller icebergs in the region. Ice island research studies have been mainly focused on their potential risks to shipping activities and offshore operations (Peterson, 2011; Mueller et al., 2013; Fuglem and Jordaan, 2017), as well as their meltwater input as they deteriorate and melt over large regions (Stern et al., 2015; Merino et al., 2016; Wagner et al., 2017; Crawford et al., 2018d).

For offshore operations, whether or not a drifting ice feature is manageable, or if activities should be suspended, depends on its speed, mass, and the number of ice features approaching the vicinity. Mass and distribution frequency are both dependent on the deterioration of each ice feature via melting and/or fracturing, processes that are associated with several atmospheric and oceanic variables that need to be considered. Therefore, it is important to evaluate the effect of metocean (meteorology and oceanography) variables on the deterioration of ice islands. However, the harsh conditions in the marine environment in the eastern Canadian Arctic make it very challenging to collect in-situ metocean data. Also, due to the difficulties involved in tracking a large number of ice islands over their lives (Merino et al., 2016; Rackow et al., 2017;

45 Stern et al., 2016), it has been a challenge to investigate the conditions that lead to ice island deterioration. An alternative way to track a large number of ice islands and monitor their deterioration is using remote sensing observations. Unlike optical methods, Synthetic Aperture Radar (SAR) imagery can produce images of ice islands even when the amount of daylight is low and cloud cover is high (Jeffries, 2002). The recent calving events of Petermann Glacier (2008-2012) and other northern Greenland glaciers have been accompanied by high-resolution satellite imagery (July 2008 to December

50 2013), which allowed tracking the ice islands throughout their periods of drift and deterioration. Through a collaboration between the Canadian Ice Service (CIS) and Water and Ice Research Lab (WIRL) at Carleton University, a large number of SAR images from the CIS archive were analyzed using a geographical information system to develop a geospatial database associated with the ice islands originally calved from Petermann Glacier in 2008-2012, as well as the Ryder, Steensby, C.H. Ostenfeld, and North Greenland ice tongues (Crawford et al., 2018a). The ice islands were delineated and monitored as they

55 deteriorated (via melting and/or fracturing) down to a threshold of $0.25 \mathrm{~km}^{2}$ in surface area (Crawford et al., 2018d), and the information was recorded in the Canadian Ice Island Drift, Deterioration and Detection (CI2D3) database. The calving events of the Petermann Glacier in 2008, 2010, 2011, and 2012 corresponded to the removal of 36, 302, 4, and $145 \mathrm{~km}^{2}$ from the Petermann Ice Tongue, respectively (Crawford et al., 2018a). The calving event that occurred in 2010 was the most significant of all and resulted in the loss of about $25 \%$ of the Petermann Glacier ice tongue (Nick et al., 2012). These calving

60 events generated numerous smaller ice islands that drifted southwards toward the Labrador Sea, which were tracked in the CI2D3 database. More information on the CI2D3 database and its documentation can be found in Desjardins et al. (2018) and Crawford et al. (2018b).

\subsection{Past studies on iceberg deterioration}

A key component for a reliable ice drift model and risk assessment of icebergs is the ability to estimate their mass (Crawford 
https://doi.org/10.5194/tc-2021-83

Preprint. Discussion started: 18 May 2021

(c) Author(s) 2021. CC BY 4.0 License.

\section{(c) (i)}

65 et al., 2018c), a variable that constantly changes as a result of melting and small/large scale fracturing as it drifts. This can be investigated through melt rate and small-scale physical calving models, field measurements, or remote sensing observations. Iceberg melt rate models predict processes such as forced convection caused by air at the iceberg sail and water at the keel, solar radiation on the iceberg sail, natural convection on sidewalls, and sidewall erosion at the waterline caused by waves (Job, 1978; El-Tahan et al., 1987; Savage, 2001). The resulting iceberg calving caused by wave erosion were modeled using

70 an empirical model (White et al., 1980; Savage, 2001) and a physical model (Wagner et al., 2014). Savage (2001) studied the relative contribution of each of these mechanisms to the overall deterioration of three different icebergs and found that wave erosion at the waterline was the dominant mechanism in contributing to the overall iceberg deterioration (by 50-65\%), followed by the resultant wave-induced calving events (by 20-30\%). Savage (2001) also found that surface melt played a minor role in the deterioration of icebergs, but it was revealed in another study that the deterioration of ice islands was

75 significantly influenced by the surface melt due to the large surface area ice islands (Crocker et al., 2013). Kubat et al. (2007) used the deterioration mechanisms described by Savage (2001) to build an operational iceberg forecasting model for the CIS. The sensitivity of the deterioration model to various metocean variables was examined, and it was revealed that the overall deterioration of icebergs was most significantly influenced by wave height (via erosion at the waterline and calving of the overhanging slabs), followed by water temperature (Kubat et al., 2007). The importance of waves and calving in the overall

80 deterioration of icebergs was also highlighted by Rackow et al. (2017) who investigated the influence of the wave-induced calving, basal melt, and buoyant convection on the deterioration of 6912 icebergs with varying sizes $\left(0.3-4717.6 \mathrm{~km}^{2}\right)$ in the Antarctic. Rackow et al., 2017 highlighted the importance of iceberg size in their thermodynamic characteristics and that while waves played the most important role in the decay of smaller icebergs $(<10 \mathrm{~km})$, basal melt was an important contributor to the overall mass loss of giant icebergs (>10 km). In a similar study, Stern et al. (2017) presented a novel

85 framework to simulate drifting tabular icebergs for climate studies. The authors modeled the melt of tabular icebergs submerged in the ocean in the Antarctic through the three mechanisms that were used in Rackow et al. (2017). Crawford et al. (2015) modeled the energy fluxes at the surface using the bulk aerodynamic approach to estimate the surface melt of an ice island, and validated the results against three surface ablation models (Kubat et al., 2007; Ballicater Consulting Ltd., 2012; Hock, 2003). Zeinali-Torbati et al. (2020) estimated the reduction in the mass of four ice island fragments offshore

90 Newfoundland using a surface ablation model (Hock, 2003), a basal ablation model (Crawford, 2018), and the observed areal surface reduction from SAR images. The authors revealed that basal melt had a greater contribution to the overall thickness melt of the ice island fragments, which was in agreement with the results of the thickness melt model in Crawford (2018). In a field study (Halliday et al., 2012), however, the melt and thinning rate of an ice island offshore Labrador was measured using ablation stakes and ground penetrating radar, and it was revealed that surface ablation contributed more than

95 basal ablation to the overall thinning rate of the ice island. In other fieldwork, Crawford et al. (2020) deployed an icepenetrating radar on an ice island originated from 2012 calving event of Petermann Glacier to measure the surface and basal ablation rates over an 11-month period. It was revealed that while basal ablation contributed to $73 \%$ of the total thinning rate, it played a minimal role in the ice island overall mass loss when compared to areal surface reduction likely caused by wave 
https://doi.org/10.5194/tc-2021-83

Preprint. Discussion started: 18 May 2021

(c) Author(s) 2021. CC BY 4.0 License.

\section{(c) (i)}

erosion, wave-induced calving, and fracture events. The authors, however, stated that basal ablation significantly influences the thickness of ice islands, which would likely increase the probability of large-scale fracture event occurrence (Crawford et al., 2020).

The deterioration mechanisms mentioned earlier describe formulations for the melt rates and small-scale calving events of icebergs caused by various metocean conditions. However, there are other mechanisms associated with iceberg deterioration (e.g., large-scale fracture caused by internal stress and convection caused by iceberg rolling), which have generally been neglected due to their infrequent occurrence. It has also been difficult to model these processes using physical models due to the lack of quantitative theories to explain these mechanisms (Savage, 2001). To date, there is no deterministic model to describe the large-scale fracture mechanisms as a function of the metocean conditions that govern these events. Additionally, the accuracy of deterministic deterioration models for glacial ice will be limited by the uncertainty in the physical parameters that govern the deterioration processes. Iceberg fracture processes have previously been studied using numerical methods to investigate fracture events for different iceberg geometries (Bassis and Jacobs, 2013), as well as due to the accumulation of microcracks in the ice structure (Bahr, 1995). Also, a recent study (Smith, 2020) investigated the fracture events of ice islands when a large protuberance develops on their keels, where a finite element analysis was used to estimate the buoyancy-driven bending stress and predict the associated fractures. However, these models did not account for the relative role of metocean conditions in the fracture processes. Probabilistic methods, however, have the ability to account

115 for the relative contribution of meteorological and hydrological conditions to the fracture events of glacial ice features. To date, no previous research has adopted probabilistic methods (e.g., Bayesian approach) to investigate ice island fracture events under the influence of the metocean conditions that control these events, likely due to the lack of reliable data. However, several studies have adopted a probabilistic approach using a Bayesian belief network and hydro-meteorological variables for navigational risk assessment of ships (Zhang et al., 2013) or to estimate the conditional probability of ship besetting in sea ice covered waters (Turnbull et al., 2019; Fu et al., 2016; Montewka et al., 2015; Montewka et al., 2013). This study uses the CI2D3 database and adopts a similar methodology to that used in Turnbull et al. (2019), Fu et al. (2016), Montewka et al. (2015), and Montewka et al. (2013) to present a probabilistic fracture model for ice islands as a function of the metocean conditions.

The CI2D3 database was previously used by Crawford et al. (2018d) to investigate the size distributions and meltwater flux of Petermann ice islands. The analysis of size distribution revealed that small ice islands constituted a significant proportion of ice island population, but large ice islands contributed the most to the total mass and melt water flux (Crawford et al., 2018d). The authors also revealed that fracture processes significantly contributed to the overall deterioration of Petermann ice islands as the ice island size distribution followed a power law model, which was corroborated by Stern et al. (2016), Tournadre et al., (2016), and Enderlin et al. (2016).

This study uses the CI2D3 database to study fracture events of the ice islands which originated from the calving events of Petermann Glacier in 2008-2012. Various atmospheric and oceanic variables are analyzed to probabilistically determine the set of conditions that lead to the highest chance of fracture event occurrence. This study first presents a 
https://doi.org/10.5194/tc-2021-83

Preprint. Discussion started: 18 May 2021

(c) Author(s) 2021. CC BY 4.0 License.

(c) (i)

description of the data structure in the CI2D3 database. Then, an overview of the results from a preliminary data analysis on the deterioration of Petermann ice islands is presented, followed by the results of the probabilistic fracture model. Finally, a validation scheme is presented to quantify the accuracy of the probabilistic fracture model.

\section{Methodology}

\subsection{Data extraction from CI2D3 database}

The CI2D3 database (version 1.1) contains data extracted from around 25,000 satellite imagery observations of ice islands from various glaciers, including the Petermann, Ryder, Steensby, C.H. Ostenfeld, and North Greenland glaciers. The data contains a geospatial polygon and 28 attribute fields for each observation. An algorithm was developed in MATLAB (version R2017b) to extract the data subsets associated with the 2008, 2010, 2011, and 2012 Petermann ice islands $(17,755$ observations). For each observation, the spatial and temporal data (latitude, longitude, and time) were extracted. Here it should be noted that the "birth" or beginning of a given ice island is considered to be immediately after it calved from another ice island (or glacier), and the "death" or end of that feature is taken as when it calves into two or more fragments.

145 By this definition, 845 ice islands were tracked in the CI2D3 database, and the lineage (parent-child relationship) between the ice islands was captured as fracture events happened. To identify the parent-child relationship, the unique identifier for each ice island observation was extracted and matched with the lineage and mother fields. This permits identification of the previous observations of each ice island back to the time it was born, which were later used for estimating the cumulative effect of variables (e.g., air and water temperatures, and waves) that each ice island experienced over its lifespan. The algorithm also used the ddinfo field to identify if the ice island was grounded or drifting at the time of observation. This was used to estimate the grounding time over the lifespan of each ice island.

\subsection{Atmospheric and oceanic data extraction}

A series of atmospheric and oceanic data were collected from reanalysis databases in the region of interest between northwest Greenland and offshore Newfoundland (46-83 $\left.{ }^{\circ} \mathrm{N}, 45-95^{\circ} \mathrm{W}\right)$ from July 2008 to December 2013. Daily average values $\left(0.3^{\circ}\right.$ spatial resolution) for zonal-meridional components of $10-\mathrm{m}$ wind velocity $\left(\mathrm{m} \mathrm{s}^{-1}\right)$ and 2 -m air temperature $\left({ }^{\circ} \mathrm{C}\right)$ were extracted from the North American Regional Reanalysis (NARR); daily average values $\left(1 / 12^{\circ}\right)$ for zonal-meridional components of ocean current velocity $\left(\mathrm{m} \mathrm{s}^{-1}\right)$ and potential water temperature $\left({ }^{\circ} \mathrm{C}\right.$ ) in 25 depth layers (down to $156 \mathrm{~m}$ ) from the Global Ocean Physics Reanalysis model in Copernicus Marine Environment Monitoring Service (CMEMS); six-hourly values $\left(1 / 8^{\circ}\right)$ for significant height of combined wind waves and swell $(m)$ and mean wave period $(s)$ from the European

160 Centre for Medium-Range Weather Forecasts (ECMWF) ERA-Interim Reanalysis; and sea ice concentration (\%) from the CIS digital daily ice charts. The extracted metocean data were linearly interpolated in space and time to the positions and times of the ice island centroids recorded in the CI2D3 database to represent the distribution of atmospheric and oceanic conditions over the drift tracks of the ice islands. 
The temporal resolution of the satellite observations in the CI2D3 database were not consistent for all ice islands six-hourly), but the temporal resolution of the images used to create the CI2D3 database range periodically from sub-daily to bi-weekly. Therefore, all atmospheric and oceanic data were extracted or averaged as daily values and then interpolated in space and time to the positions and times of the ice island observations.

\subsection{Probabilistic model development}

170 To evaluate the conditional dependence of ice island fracture events on atmospheric and oceanic variables, a Bayesian approach was employed. Bayesian analysis is a well-used method in probabilistic studies to evaluate the probability of a certain outcome using the most salient variables (Gutierrez et al., 2011). This method is recognized by its strong reasoning ability in uncertain situations and its ability to combine and analyze data from various datasets (Fu et al., 2016). Using the Bayesian method, the dependency and independency of a set of variables (Figure 1-a) were analyzed via a directed acyclic graph (Figure 1-b). Initially, the distribution of 10 atmospheric and oceanic variables were studied. These included wind speed $\left(V_{w}\right)$, air temperature $\left(T_{a}\right)$, ocean current speed $\left(V_{c}\right)$, water temperature $\left(T_{w}\right)$, wave energy index $\left(E_{w}\right)$, lifetime mean air temperature $\left(T_{a_{\_} a v g}\right)$, lifetime mean water temperature $\left(T_{a_{\_} a v g}\right)$, lifetime mean wave energy index $\left(E_{w_{\_} a v g}\right)$, grounding time $\left(t_{g}\right)$, and sea ice concentration $\left(C_{s i}\right)$. Wind and current speeds were estimated as the magnitude of the extracted zonalmeridional components for wind and ocean currents, respectively. Water temperature was estimated as the average of water temperatures at all layers from the water surface down to a depth of $50 \mathrm{~m}$. Given that wave energy flux is proportional to mean wave period and significant wave height squared (Christakos et al., 2020; Akpınar et al., 2019; Waters, 2008; Falnes, 2007), the wave energy index was defined as:

$E_{w}=\left(H_{\text {wave }}\right)^{2}\left(T_{\text {wave }}\right)$,

where $H_{\text {wave }}$ represents the significant height of combined wind waves and swell $(m)$ and $T_{\text {wave }}$ represents the mean wave period $(s)$. Time since previous calving was also explored as a variable, but this had very little predictive power and was excluded from subsequent analyses. However, in order to capture the cumulative effect of temperature and waves over the lifespan of the ice island, we first identified all previous observations of each ice island back to the time and location that it was born. Then, the air and water temperatures, and wave energy index were interpolated spatially and temporally to all previous observations. To exclude the effect of observation frequency, these variables were interpolated in space and time to a daily interval. The cumulative values were then calculated as the sum of the daily-average variables over the lifespan of the ice island. These cumulative values were then normalized by the lifespan of the ice island to effectively compute the lifetime mean wave energy index, as well as the mean air and water temperatures over the lifespan of the ice island, which differ from positive degree day calculations that are often used in ice melt rate models (e.g., Hock, 2003). Grounding time was estimated by adding the number of days that an ice island was grounded over its lifespan. The distribution of these variables around fractured ice islands and all ice island observations were investigated and compared. However, further analysis of 
$195 E_{w_{-} a v g}$ and $t_{g}$ distributions for fracture events and all observations identified no correlation between these variables and the occurrence of fracture events, so they were excluded from the Bayesian fracture model development. Also, studying the sea ice cover around the ice island observations showed that sea ice concentrations were less than 3/10ths for about $99 \%$ of the observations, so it was discarded from further analysis as a model input variable.

(a)

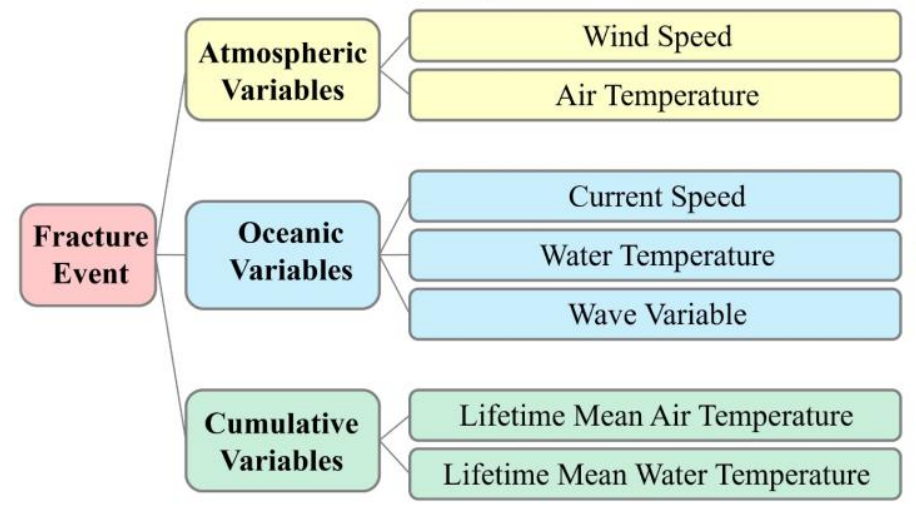

(b)

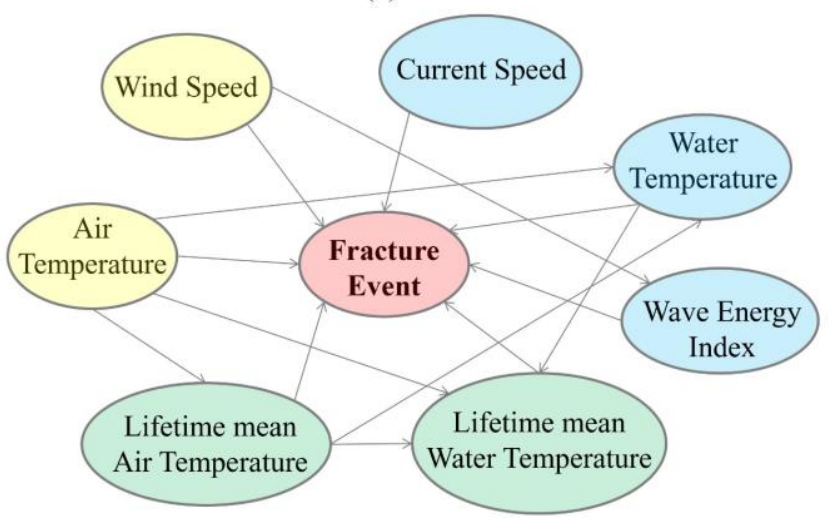

200 Figure 1. The classification of variables for the Bayesian fracture network (a), and the associated directed acyclic graph that shows the inter-relationship between the variables with the arrowheads showing the causality (b)

The distribution of the metocean variables presented in Fig. 1 were studied for all ice island observations and compared against the variable distributions at the time of fracture events. However, the extracted reanalysis data revealed different number of data points available for the analysis of the seven variables presented. For example, for wind speed and air temperature, 17735 data points were available for all observations of Petermann ice islands. For current speed and water temperature, 16791 and 16784 data points were available for all observations of Petermann ice islands, respectively. These points covered most of the spatial and temporal records from the CI2D3 database. However, for wave energy index, only 3985 data points from all observations were available during the same time period. Similarly, different number of data points were available for each variable during the fracture events. The different numbers of data points for each variable are likely due to the fact that the ice islands drifted some time near coastlines, and these data were extracted from reanalysis models that have insufficient spatial resolution to model data close to the coastlines. Therefore, the distributions of the studied variables from all observations and fractured subset are represented by relative frequencies to allow for consistent comparison of these distributions.

The correlation between a pair of variables was investigated using the Pearson Product-Moment Correlation 215 coefficient $(r)$, given by (Freedman et al., 2010):

$r=\frac{\sum_{i}^{n}\left(x_{i}-\bar{x}\right)\left(y_{i}-\bar{y}\right)}{\sqrt{\sum_{i}^{n}\left(x_{i}-\bar{x}\right)^{2}} \sqrt{\sum_{i}^{n}\left(y_{i}-\bar{y}\right)^{2}}}$

where $x_{i}, y_{i}$ are a pair of variables for the $i^{\text {th }}$ set of data and $\bar{x}, \bar{y}$ are the means of variables $x, y$ from all observations $(n)$. The full set of data was used to perform the correlation analysis, and the inter-relationships between the variables is 
presented in Figure 1-b. Directed arrows were drawn from each variable to all of the variables that showed a correlation coefficient greater than 0.35 .

The probability of fracture event occurrence in extremely high metocean conditions was investigated using a full set of model criteria with the high state $\left(>x^{*}\right)$ of each variable. The selected criteria $\left(x^{*}\right)$ for each variable were identified by varying each criterion over the range of each variable from the fracture subset to maximize the fracture event probability. The distribution of conditional posterior probability was calculated through Bayes' Theorem, given by (Stuart and Ord, 1994):

$P(X \mid Y)=\frac{P(X) P(Y \mid X)}{P(Y)}$,

where $P(X)$ is the prior probability of fracture event occurrence, $P($ Frac $) ; P(Y \mid X)$ is the likelihood of a specific criteria set occurrence during fracture events, $P\left(V_{w}, T_{a}, V_{c}, T_{w}, E_{w}, T_{a_{-} a v g}, T_{w_{-} a v g} \mid F r a c\right)$; and $P(Y)$ is the evidence of the criteria set occurrence for all observations, $P\left(V_{w}, T_{a}, V_{c}, T_{w}, E_{w}, T_{a_{-} a v g}, T_{w_{-} a v g}\right)$. The probabilities in Eq. (3) should be recalculated when new evidence become available, a process that reduces the dependence of the posterior probability on the original estimated prior probability (Eleye-Datubo et al., 2006). The values of $P(Y \mid X)$ and $P(Y)$ were determined using the relative frequency 230 of the set of states in fracture events and all observations, respectively. The relative frequency is given by (Bonafede and Giudici, 2007):

$P\left(S_{i}\right)=\frac{n_{i}}{n}$,

where $S_{i}$ represents a set of the variables' states, $n_{i}$ represents the frequency of the observed set of the states in fracture events or all observations, and $n$ represents the total number of fracture events or all observations in the dataset.

Table 1. Various states of atmospheric and oceanic variables for the Bayesian fracture model

\begin{tabular}{cccc}
\hline Variables & Unit & State 1 & State 2 \\
\hline Wind Speed $\left(\boldsymbol{V}_{\boldsymbol{w}}\right)$ & $\left(\mathrm{m} \mathrm{s}^{-1}\right)$ & $\leq V_{w-\tilde{x}}$ & $>V_{w-\tilde{x}}$ \\
Air Temperature $\left(\boldsymbol{T}_{\boldsymbol{a}}\right)$ & $\left({ }^{\circ} \mathrm{C}\right)$ & $\leq T_{a-\tilde{x}}$ & $>T_{a-\tilde{x}}$ \\
Current Speed $\left(\boldsymbol{V}_{\boldsymbol{c}}\right)$ & $\left(m s^{-1}\right)$ & $\leq V_{c-\tilde{x}}$ & $>V_{c-\tilde{x}}$ \\
Water Temperature $\left(\boldsymbol{T}_{\boldsymbol{w}}\right)$ & $\left({ }^{\circ} \mathrm{C}\right)$ & $\leq T_{w-\tilde{x}}$ & $>T_{w-\tilde{x}}$ \\
Wave Energy Index $\left(\boldsymbol{E}_{\boldsymbol{w}}\right)$ & $\left(m^{2} s\right)$ & $\leq E_{w-\tilde{x}}$ & $>E_{w-\tilde{x}}$ \\
Lifetime Mean Air Temperature $\left(\boldsymbol{T}_{\boldsymbol{a}_{\_} \text {avg }}\right)$ & $\left({ }^{\circ} \mathrm{C}\right)$ & $\leq T_{a_{-} a v g-\tilde{x}}$ & $>T_{a_{\_} a v g-\tilde{x}}$ \\
Lifetime Mean Water Temperature $\left(\boldsymbol{T}_{\boldsymbol{w} \_ \text {avg }}\right)$ & $\left({ }^{\circ} \mathrm{C}\right)$ & $\leq T_{w_{-} \text {avg }-\tilde{x}}$ & $>T_{w_{-} a v g-\tilde{x}}$
\end{tabular}

$-\bar{x}$ represents the median value in the distribution of the given variable

To calculate the probability of fracture events in different metocean conditions, the ranges of atmospheric and oceanic variables at the time of fracture events were first divided into two states (Table 1) using the variable distribution medians (as specified by $\tilde{x}$ ). The conditional fracture probabilities were then estimated using a similar Bayesian approach 
https://doi.org/10.5194/tc-2021-83

Preprint. Discussion started: 18 May 2021

(c) Author(s) 2021. CC BY 4.0 License.

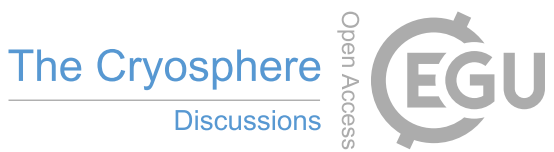

(Eq. (3)) through analyzing concurrent atmospheric and oceanic conditions at the time of fracture events that were extracted

from the entire record for all ice island observations. Due to the limited number of fracture events (328), the number of state combinations in the presented model needed to be reduced to avoid model saturation and increase the model reliability. Among the atmospheric and oceanic variables analyzed in this study, current speed played an insignificant role in the fracture events of the ice islands, so it was not considered for further analysis.

\section{Results and discussion}

\section{3.1 Preliminary analysis of ice island fracture events}

The descendants of ice islands resulting from the calving events of Petermann Glacier in 2008, 2010, 2011, and 2012 generally drifted in a southward direction toward the Labrador Sea (Figure 2-a). These ice islands experienced 328 fracture events over their lives (Figure 2-b), which resulted in 845 ice islands. The 2010 event calved the largest ice island (Table 2), which generated 637 ice islands through its fractures (242 times), some of which drifted as far as offshore Newfoundland (Figure 2-a). The second largest calving event happened in 2012 which generated 169 ice islands through 73 fracture events, but the resulting ice islands were only recorded as far as offshore Iqaluit, given that the monitoring period in the CI2D3 database ended in December 2013. The other two calving events (2008 and 2011) generated 29 and 10 ice islands, which resulted from nine and four calving events, respectively. The size distribution of ice islands showed that large ice islands $\left(>10 \mathrm{~km}^{2}\right)$ drifted longer before undergoing a fracture event and split into greater numbers of pieces per fracture event.

255 Examples of this are two large ice islands $\left(\sim 137 \mathrm{~km}^{2}\right.$ and $\left.60 \mathrm{~km}^{2}\right)$ originating from the 2010 calving event, which generated nine distinct pieces upon fracturing. However, around $70 \%$ of all fracture events generated only two daughter ice islands. A more detailed drift and deterioration analysis of the Petermann ice islands is presented in Zeinali-Torbati et al. (2019).

(a)

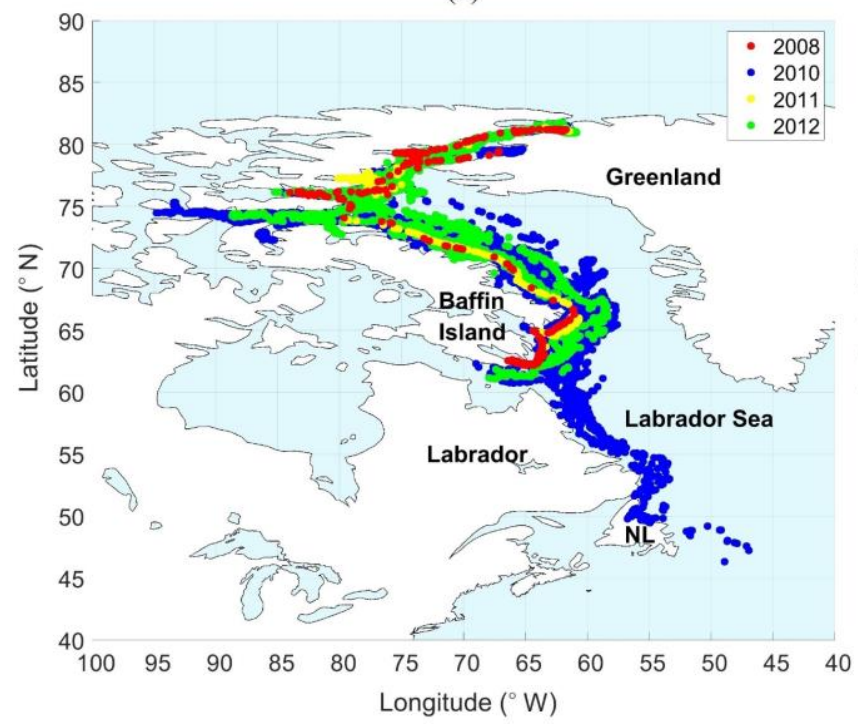

(b)

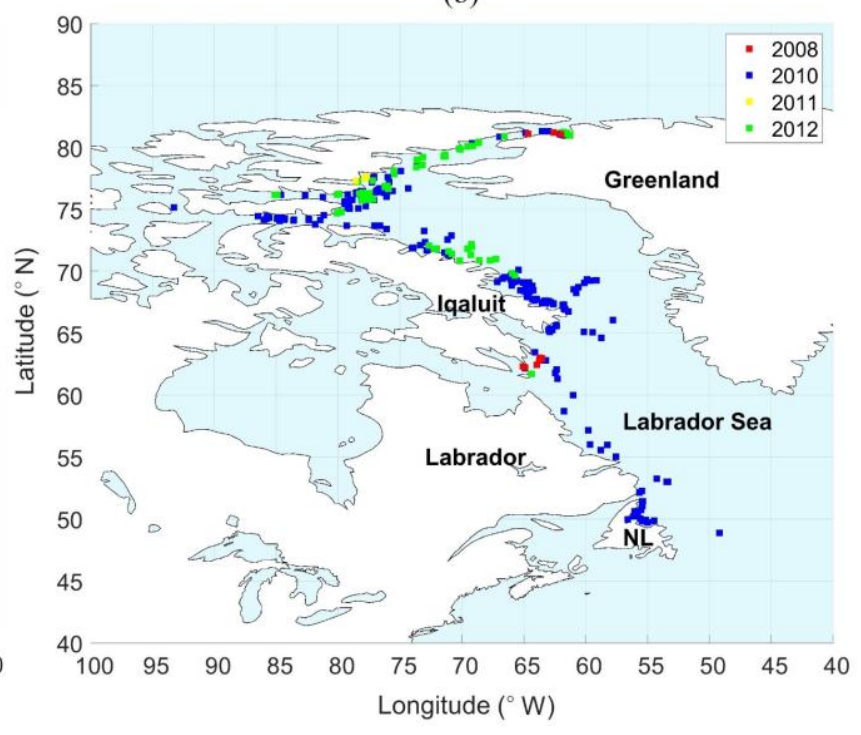


https://doi.org/10.5194/tc-2021-83

Preprint. Discussion started: 18 May 2021

(c) Author(s) 2021. CC BY 4.0 License.

(c) (i)

Figure 2. The drift trajectories (a) and the locations of fracture events (b) for the ice islands originating from the calving events of the Petermann Glacier in 2008 (red), 2010 (blue), 2011 (yellow), and 2012 (green)

Table 2. Description of the ice islands originating from the massive calving events of Petermann Glacier in 2008, 2010, 2011, and 2012

\begin{tabular}{ccccc}
\hline $\begin{array}{c}\text { Glacier } \\
\text { calving } \\
\text { year }\end{array}$ & $\begin{array}{c}\text { Main } \\
\text { calving } \\
\text { date }\end{array}$ & $\begin{array}{c}\text { Surface } \\
\text { area } \\
\left(\mathbf{k m}^{2}\right)\end{array}$ & $\begin{array}{c}\text { Number of } \\
\text { digitized } \\
\text { polygons }\end{array}$ & $\begin{array}{c}\text { Number of } \\
\text { fracture } \\
\text { events }\end{array}$ \\
\hline $\mathbf{2 0 0 8}$ & $\begin{array}{c}\text { 10 July } \\
\text { 5 August }\end{array}$ & 36.4 & 332 & 9 \\
$\mathbf{2 0 1 0}$ & $\begin{array}{c}\text { 16 August } \\
\text { 21 September } \\
\mathbf{2 0 1 1}\end{array}$ & 402.4 & 9658 & 242 \\
$\mathbf{2 0 1 2}$ & 17 July & 144.6 & 502 & 4 \\
\hline
\end{tabular}

\subsection{Distributions of atmospheric and oceanic variables}

The atmospheric, oceanic, and lifetime mean variables shown in Figure 1 were examined at the time of ice island fracture

events, and then compared with the metocean conditions for all ice island observations using the methodology described earlier. Figure 3 through Figure 5 show the summary statistics and histogram plots of the relative frequency of regional metocean variables surrounding the Petermann ice islands from all observations (blue), as well as from the fracture events (red).

Figure 3-a shows that the mean water temperature surrounding all Petermann ice islands was negative $\left(-0.8^{\circ} \mathrm{C}\right)$ indicating that they mainly drifted within cold waters; however, the water temperature values reached up to $10.4{ }^{\circ} \mathrm{C}$. The statistics for lifetime mean water temperature from all observations (Figure 3-c) were almost the same as water temperature: a negative mean value of $-0.8{ }^{\circ} \mathrm{C}$ and a range of $-1.8^{\circ} \mathrm{C}$ to $10.4{ }^{\circ} \mathrm{C}$. Comparing the distribution of water temperatures in Figure 3-a,b reveals that fracture events happened at higher water temperatures; while only $20 \%$ of ice islands from the entire dataset were surrounded by water temperatures above $0{ }^{\circ} \mathrm{C}, 42 \%$ of fractured ice islands were subjected to positive water temperatures. In a similar way, it was revealed from long-term water temperature distributions that only $13 \%$ of the ice islands from all observations drifted in positive lifetime mean water temperatures (Figure 3-c). This, however, corresponded to about $34 \%$ of the ice islands in the fracture subset (Figure 3-d). The summary statistics presented in Figure 3 reveal that water temperature and lifetime mean water temperature played significant roles in the fracture events of Petermann ice islands; compared to the temperature records for all ice island observations, the ice islands at the time of fracture events experienced, on average, $1.1{ }^{\circ} \mathrm{C}$ and $0.8^{\circ} \mathrm{C}$ greater values of water temperature and lifetime mean water temperature, respectively. This indicates the important contribution of warm waters to faster deterioration of glacial ice features (as stated by Kubat et al., 2007), likely due to higher internal stress caused by the increased heat transfer from water to the ice feature. 
https://doi.org/10.5194/tc-2021-83

Preprint. Discussion started: 18 May 2021

(c) Author(s) 2021. CC BY 4.0 License.

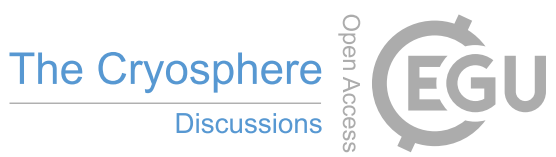

(a)

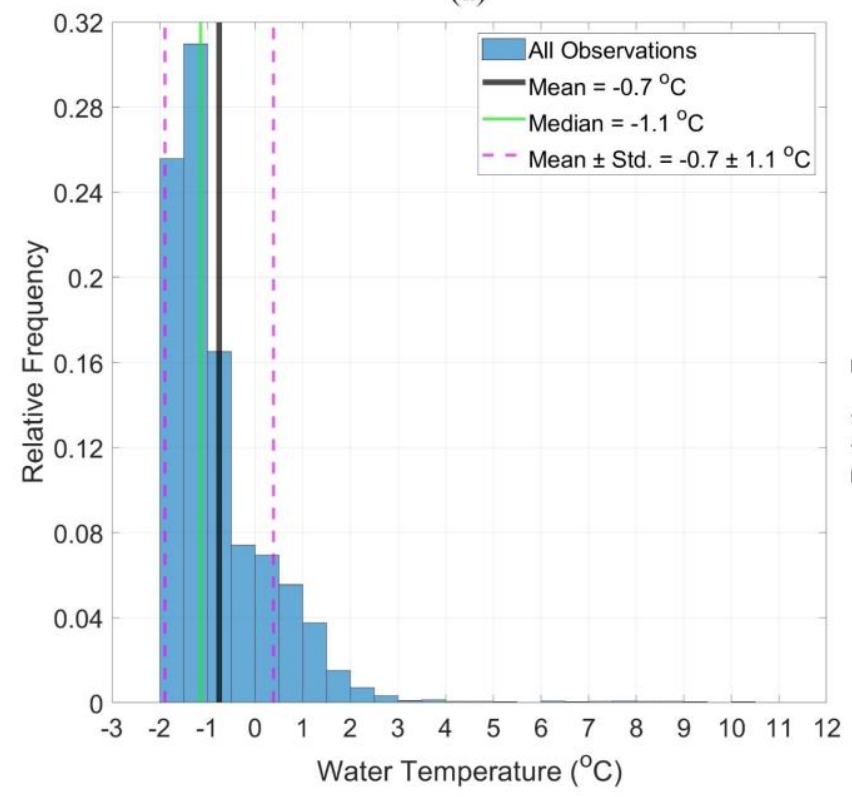

(c)

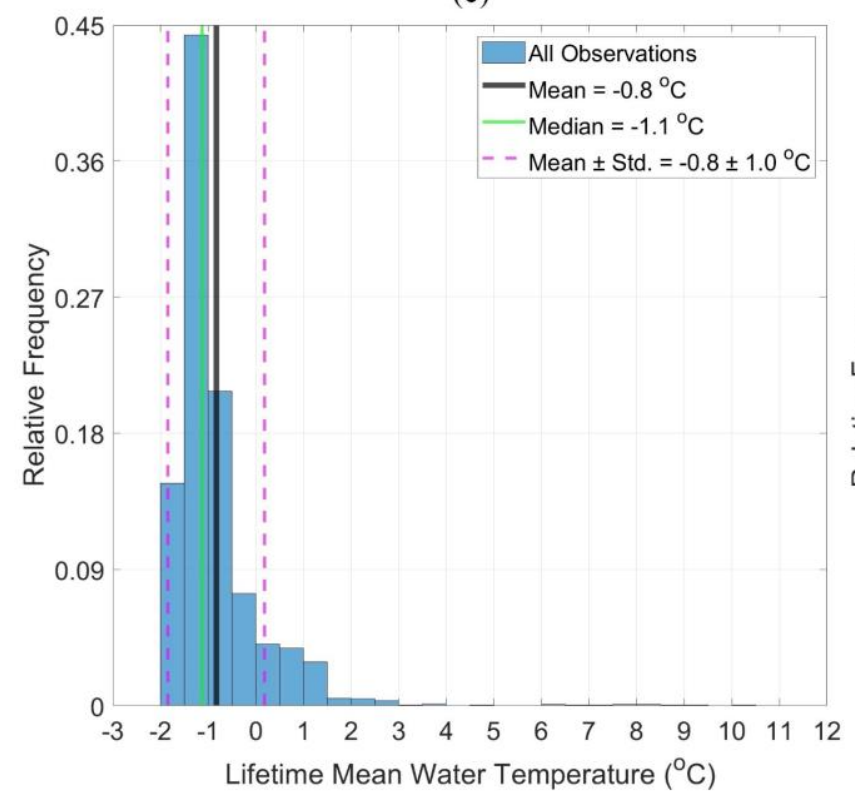

(b)

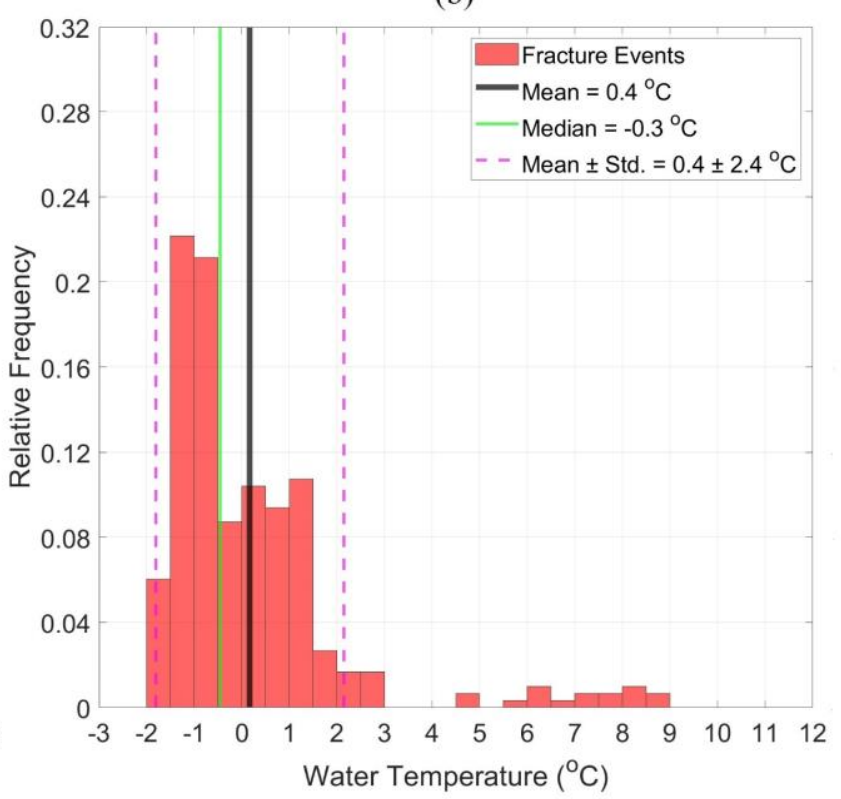

(d)

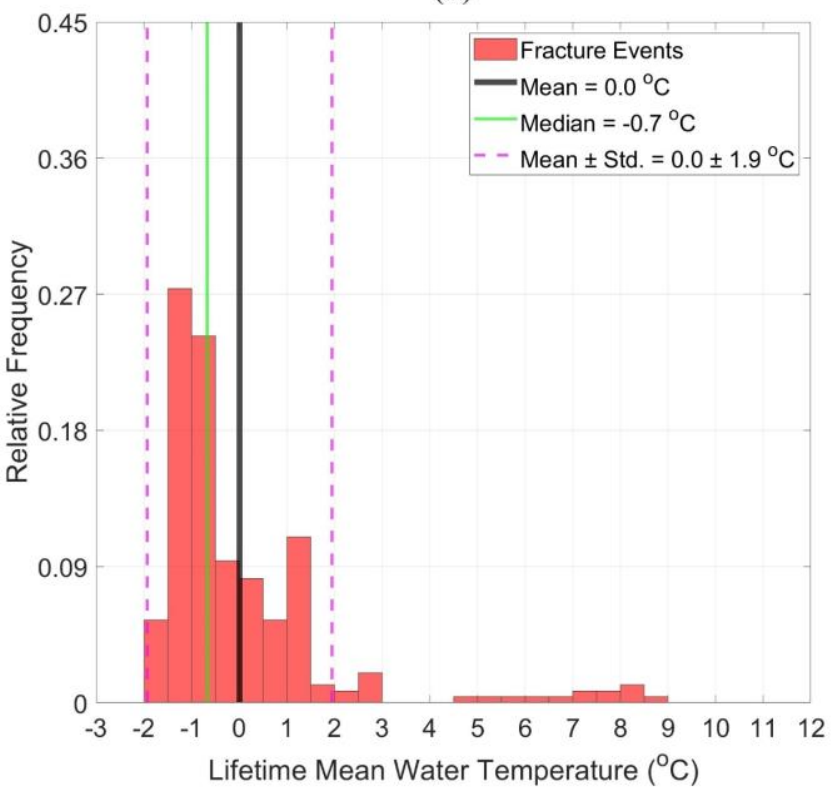

Figure 3. Relative frequency histogram plots of water temperature $(a ; n=16784, b ; n=298)$ and lifetime mean water

temperature ( $c ; n=13537, d ; n=256)$ surrounding Petermann ice islands for all observations $(a, c)$, and for the fracture events $(\mathrm{b}, \mathrm{d})$

Figure 4-a shows that the air temperatures to which the ice islands were subjected ranged from $-35.6{ }^{\circ} \mathrm{C}$ to $17.9^{\circ} \mathrm{C}$ for all observations, but the mean air temperature of $-9.4^{\circ} \mathrm{C}$ reveals that the ice islands drifted a significant amount of time in 
https://doi.org/10.5194/tc-2021-83

Preprint. Discussion started: 18 May 2021

(c) Author(s) 2021. CC BY 4.0 License.

(c) (i)

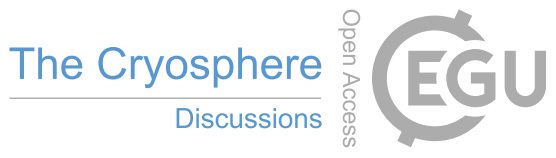

cold air temperatures. Similarly, the Petermann ice islands were mainly subjected to negative lifetime mean air temperatures

290 with an average of $-11.6^{\circ} \mathrm{C}$ ranging from $-33.7^{\circ} \mathrm{C}$ to $17.9^{\circ} \mathrm{C}$ (Figure 4-c). Investigation of air temperature and its long-term effect at the time of fracture events (Figure 4-b,d) revealed that, on average, the ice islands were subjected to much higher values of these variables. The average air temperature at the time of fracture events was $-5.2{ }^{\circ} \mathrm{C}$, which was $4.2{ }^{\circ} \mathrm{C}$ higher than the mean air temperature surrounding all ice islands. In a similar way, the ice islands from the fracture subset were, on average, subjected to $5.7^{\circ} \mathrm{C}$ higher lifetime mean air temperature than the ice islands from all observations. The air 295 temperature distributions (Figure 4-a,b) show that while the air temperatures associated with all ice island observations were most frequent around $0{ }^{\circ} \mathrm{C}$, the values associated with the fracture events were most frequent between $0{ }^{\circ} \mathrm{C}$ and $4{ }^{\circ} \mathrm{C}$. This, along with a $4.2^{\circ} \mathrm{C}$ higher mean air temperature value from the fracture subset indicate that higher air temperature values are likely linked with the occurrence of fracture events. The analysis of lifetime mean air temperature distributions over the lifespan of each ice island (Figure 4-c,d) revealed that while only $14 \%$ of all ice island observations experienced lifetime mean air temperatures greater than $0{ }^{\circ} \mathrm{C}$, about $35 \%$ of the ice islands from the fracture subset were subjected to positive lifetime mean air temperatures. This indicates that the long exposure of ice islands to relatively warm air temperatures was likely an important factor in the occurrence of the fracture events. 
(a)

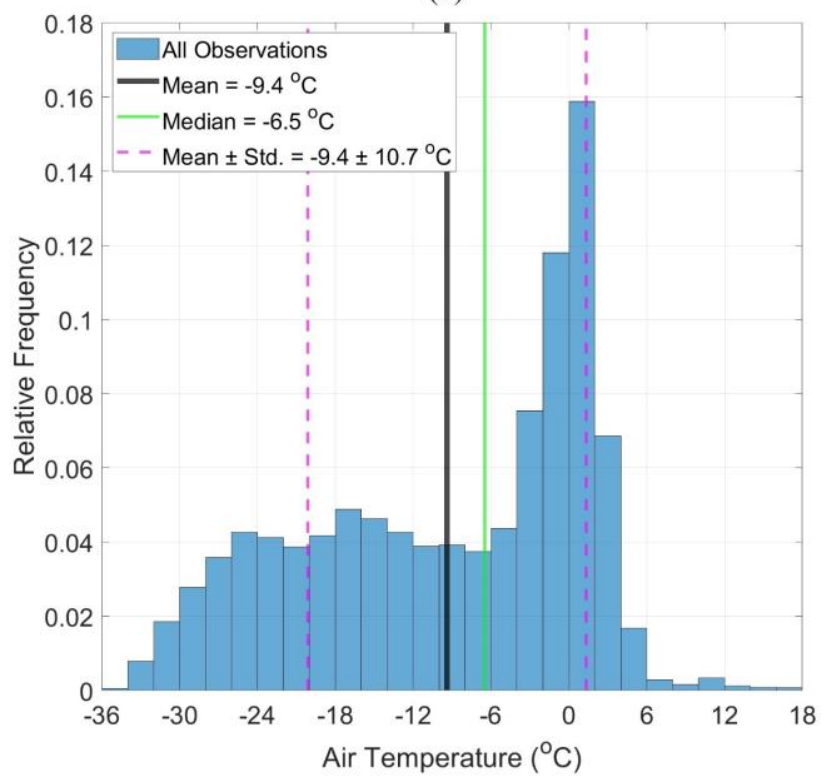

(c)

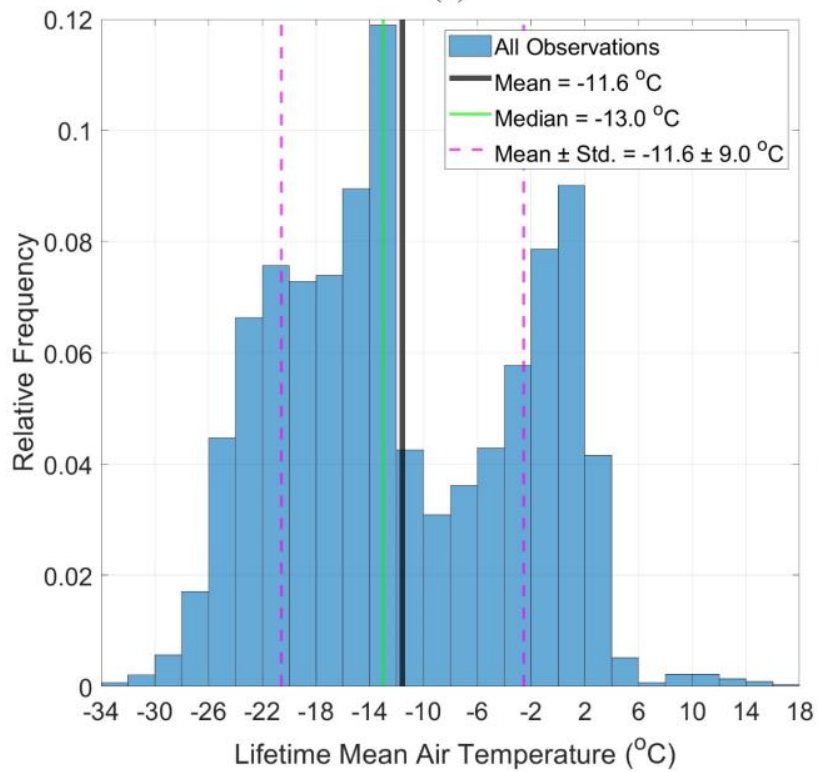

(b)

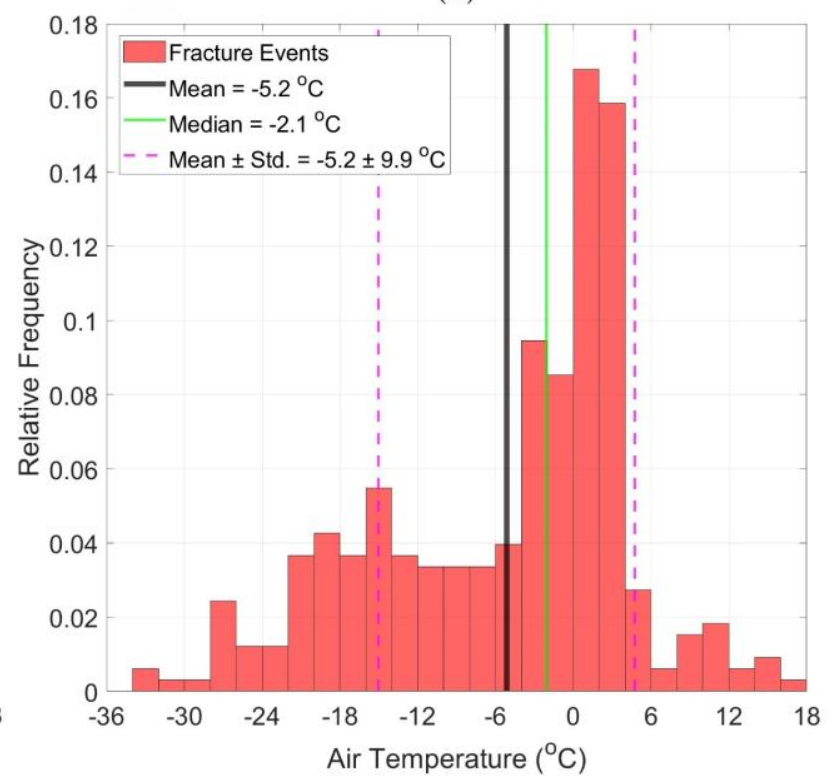

(d)

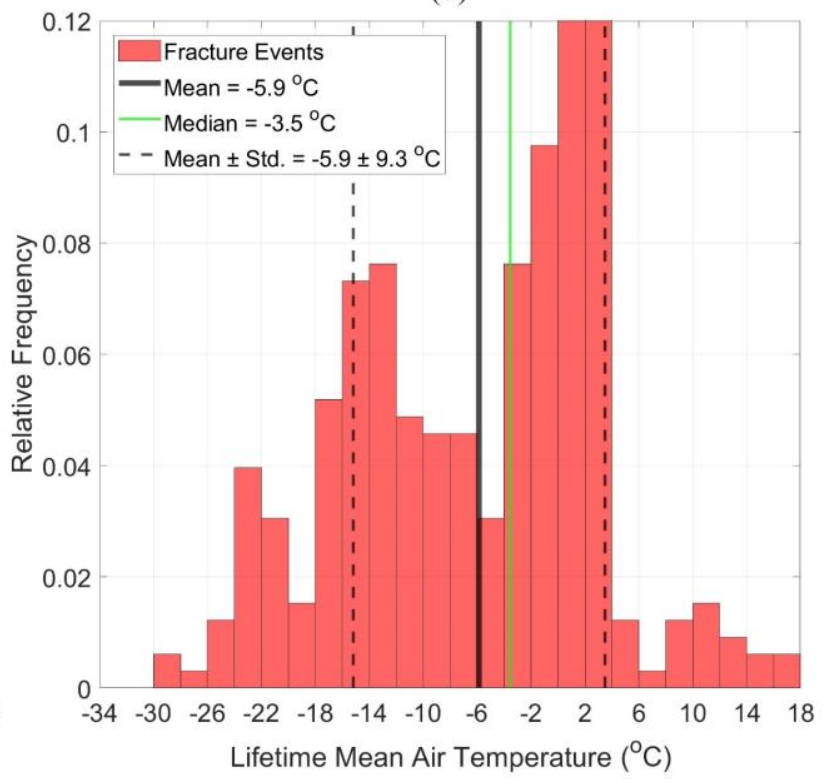

Figure 4. Relative frequency histogram plots of air temperature $(a ; n=17735, b ; n=328)$ and lifetime mean air temperature (c; $\mathrm{n}=17755, \mathrm{~d} ; \mathrm{n}=328$ ) surrounding Petermann ice islands for all observations (a,c), and for the fracture events (b,d)

The results associated with all observations of waves (Figure 5-a) show that while the wave energy index values varied from $0.1 \mathrm{~m}^{2} \mathrm{~s}$ to $62.1 \mathrm{~m}^{2} \mathrm{~s}$, the ice islands were mainly subjected to relatively low wave energy index with an average value of $5.3 \mathrm{~m}^{2} \mathrm{~s}$. Similarly, the regional wind and current speeds surrounding the ice islands from all observations were often relatively low, with a mean value of $2.9 \mathrm{~m} \mathrm{~s}^{-1}$ and $0.08 \mathrm{~m} \mathrm{~s}^{-1}$, respectively (Figure 5-c,e). The summary 
https://doi.org/10.5194/tc-2021-83

Preprint. Discussion started: 18 May 2021

(c) Author(s) 2021. CC BY 4.0 License.

(c) (i)

310 statistics of the records from the fracture events (Figure 5-b,d,f) revealed that the regional mean wave energy index, wind speed, and current speed around the ice islands at the time of fracture events were slightly stronger (by 38\%, 17\%, and 38\%, respectively) when compared to the associated values for all ice islands observations. The analysis of wave energy index distributions around the Petermann ice islands presented in Figure 5-a,b show that only $30 \%$ of Petermann ice islands encountered wave energy index values greater than $6 \mathrm{~m}^{2} \mathrm{~s}$. The fracture events, however, occurred at greater wave energy 315 index values, where $46 \%$ of ice island observations experienced wave energy index values greater than $6 \mathrm{~m}^{2} \mathrm{~s}$. The analysis also shows that while relatively high values of wave energy index most likely contribute to the occurrence of ice island fracture events, this variable by itself does not lead to a high fracture probability of Petermann ice islands. Investigation of wind speeds over the ice islands (Figure 5-c,d) showed that the ice islands from all observations were subjected most frequently to weak winds $\left(\sim 1-3 \mathrm{~m} \mathrm{~s}^{-1}\right)$. Similarly, at the time of fracture events, the ice islands were most frequently subjected to weak winds $\left(\sim 2-4 \mathrm{~m} \mathrm{~s}^{-1}\right)$. The fact that there is little difference in these distributions suggests that wind speed by itself was not a significant variable in the fracture of ice islands. The comparison of ocean current speed records around the studied ice islands (Figure 5-e,f) revealed that the current speed values from the fracture subset were slightly greater than the full observational records. However, similar to all records, the fractured ice islands were mainly subjected to weak regional current speeds, which suggests minor contribution of current speed to the fracture event occurrence. 
https://doi.org/10.5194/tc-2021-83

Preprint. Discussion started: 18 May 2021

(c) Author(s) 2021. CC BY 4.0 License.

(a)

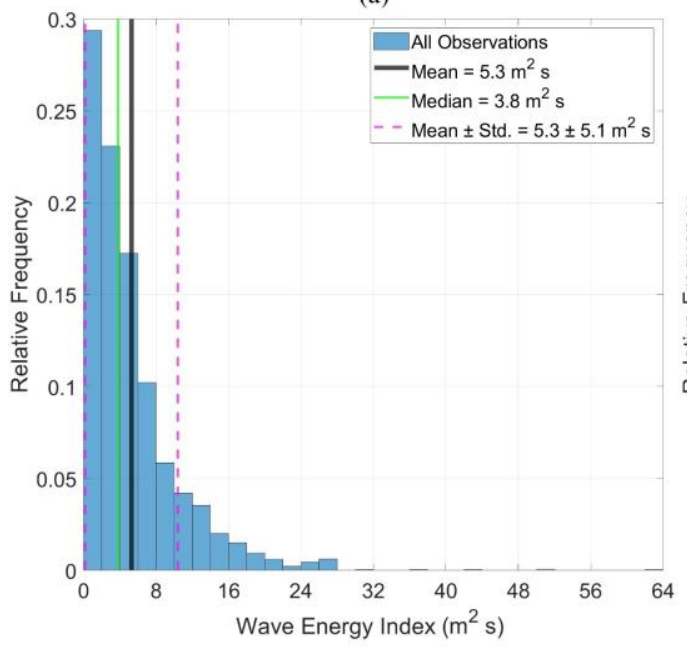

(c)

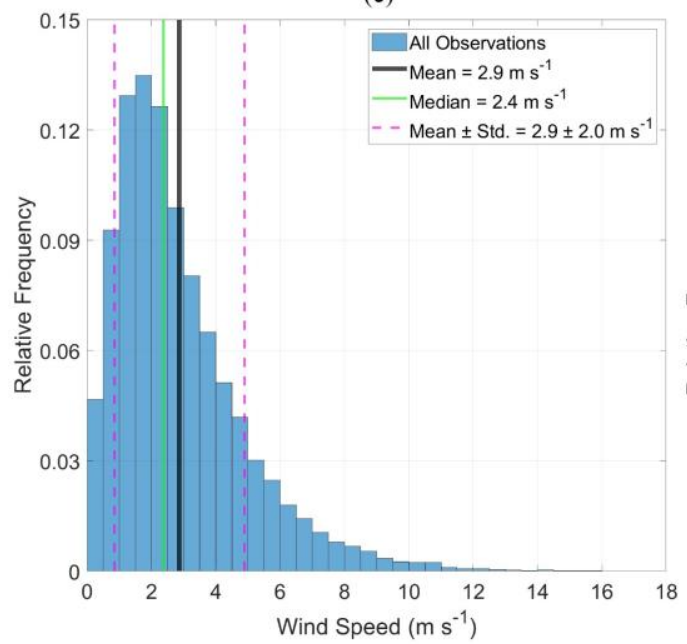

(e)

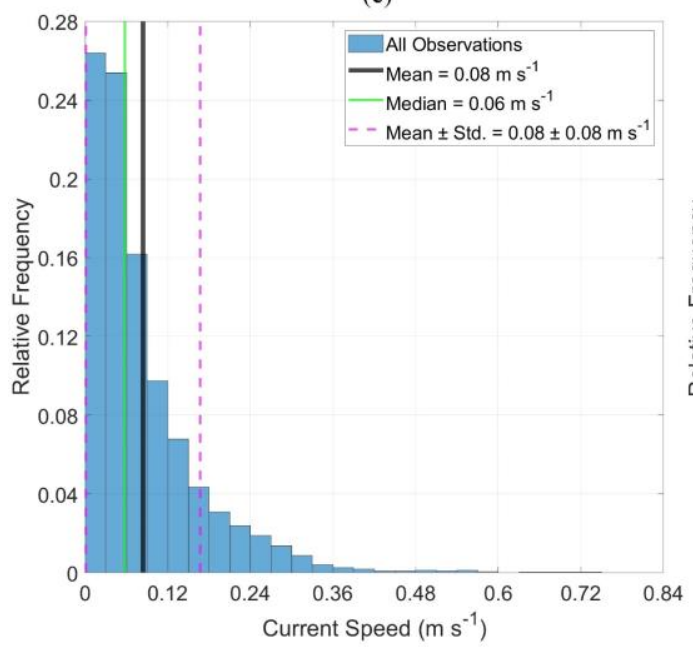

(b)

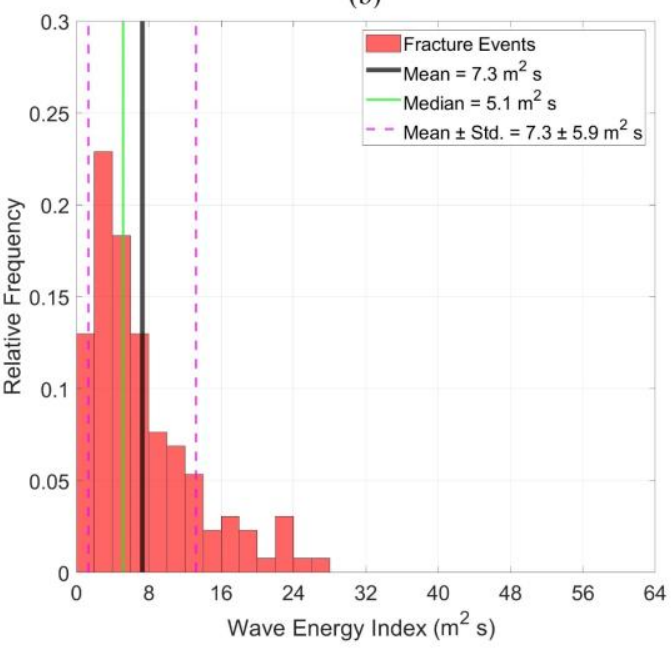

(d)

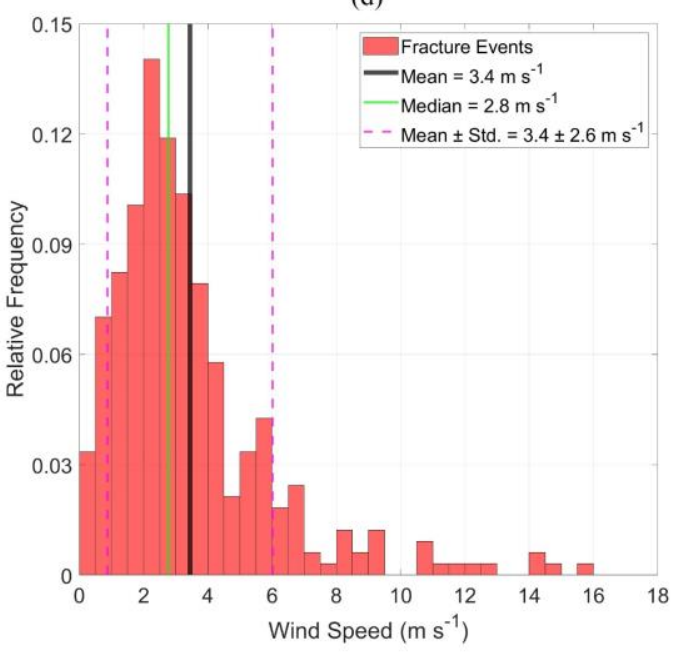

(f)

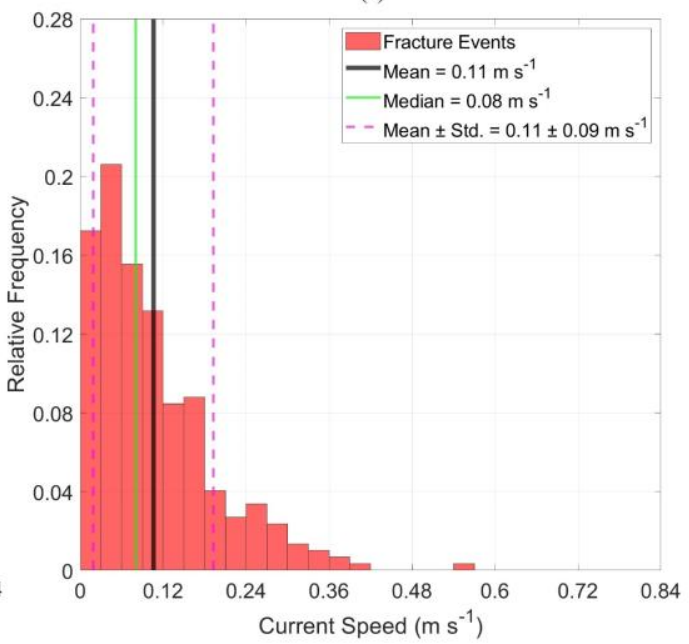


Figure 5. Relative frequency histogram plots of wave energy index ( $a ; n=3985, b ; n=131)$, wind speed (c; $n=17735$, d; $\mathrm{n}=328$ ), and current speed (e; $\mathrm{n}=16791, \mathrm{f} ; \mathrm{n}=296)$ surrounding Petermann ice islands for all observations (a,c,e), and for the fracture events $(\mathrm{b}, \mathrm{d}, \mathrm{f})$

The pairwise correlation between the metocean variables revealed that water temperature was positively correlated with the air temperature, a finding that was stated in a number of other studies (e.g., Morrill et al., 2001; Erickson and Stefan, 2000). Table 3 also revealed a correlation between the wind speed and wave energy index, which was expected as the wave energy index is dependent on the significant wave height (Eq. (1)). The positive correlation between wind speed and wave height was also stated in Fu et al. (2016). Other inter-relationships between the variables include the correlations between the daily-average air/water temperatures and the lifetime mean air/water temperatures. These correlations are expected given that the lifetime mean variables were defined as the time-average of daily-average variables over the life of each ice island.

Table 3. Pearson product-moment correlation coefficients of the metocean variables in the developed fracture model. The variables included water temperature $\left(\boldsymbol{T}_{\boldsymbol{w}}\right)$, wind speed $\left(\boldsymbol{V}_{\boldsymbol{w}}\right)$, air temperature $\left(\boldsymbol{T}_{\boldsymbol{a}}\right)$, current speed $\left(\boldsymbol{V}_{\boldsymbol{c}}\right)$, wave energy index $\left(\boldsymbol{E}_{\boldsymbol{w}}\right)$, lifetime mean air temperature $\left(\boldsymbol{T}_{\boldsymbol{a} \_ \text {avg }}\right)$, and lifetime mean water temperature $\left(\boldsymbol{T}_{\boldsymbol{w} \_ \text {avg }}\right)$

\begin{tabular}{cccccccc}
\hline Variable & $\boldsymbol{V}_{\boldsymbol{w}}$ & $\boldsymbol{T}_{\boldsymbol{a}}$ & $\boldsymbol{V}_{\boldsymbol{c}}$ & $\boldsymbol{T}_{\boldsymbol{w}}$ & $\boldsymbol{E}_{\boldsymbol{w}}$ & $\boldsymbol{T}_{\boldsymbol{a} \_ \text {avg }}$ & $\boldsymbol{T}_{\boldsymbol{w} \_ \text {avg }}$ \\
\hline $\boldsymbol{V}_{\boldsymbol{w}}$ & 1 & & & & & \\
$\boldsymbol{T}_{\boldsymbol{a}}$ & 0.132 & 1 & & & & \\
$\boldsymbol{V}_{\boldsymbol{c}}$ & 0.097 & 0.079 & 1 & & & \\
$\boldsymbol{T}_{\boldsymbol{w}}$ & 0.236 & 0.547 & 0.076 & 1 & & \\
$\boldsymbol{E}_{\boldsymbol{w}}$ & 0.403 & 0.046 & 0.066 & 0.232 & 1 & \\
$\boldsymbol{T}_{\boldsymbol{a} \_ \text {avg }}$ & 0.216 & 0.650 & 0.145 & 0.581 & 0.097 & 1 \\
$\boldsymbol{T}_{\boldsymbol{w} \_ \text {avg }}$ & 0.265 & 0.366 & 0.153 & 0.847 & 0.297 & 0.647 & 1 \\
\hline
\end{tabular}

340 The associated $\mathrm{p}$-values for all correlations show significance at the level of 0.00005 (p-value $<0.00005$ ).

\subsection{Metocean conditional criteria sets and fracture event frequency}

To examine the probability of fracture event occurrence in very high states of metocean conditions, a full set of model criteria associated with the atmospheric and oceanic conditions at the time of fracture events was obtained and presented as criteria set $\mathrm{i}=6$ (Table 4), using the methodology described earlier. The same approach was employed to investigate the influence of simplifying the fracture model using fewer number of variables, and the results were presented by criteria sets $\mathrm{i}=1-5$ in Table 4 ).

Table 4. Fracture model conditional criteria sets and the associated conditional probability $\left(P_{\text {frac }}\right)$. The variables included water temperature $\left(T_{w}\right)$, wind speed $\left(V_{w}\right)$, air temperature $\left(T_{a}\right)$, current speed $\left(V_{c}\right)$, wave energy index $\left(E_{w}\right)$, lifetime mean air temperature $\left(T_{a_{\_} a v g}\right)$, and lifetime mean water temperature $\left(T_{w_{-} a v g}\right)$ 


\begin{tabular}{c|ccccccc|c}
\hline $\begin{array}{c}\text { Criteria } \\
\text { Set i }\end{array}$ & $\begin{array}{c}\boldsymbol{T}_{w} \\
\left({ }^{\circ} \mathrm{C}\right)\end{array}$ & $\begin{array}{c}\boldsymbol{V}_{w} \\
\left(\boldsymbol{m} \boldsymbol{~ s}^{-\mathbf{1}}\right)\end{array}$ & $\begin{array}{c}\boldsymbol{T}_{\boldsymbol{a}} \\
\left({ }^{\circ} \mathrm{C}\right)\end{array}$ & $\begin{array}{c}\boldsymbol{V}_{\boldsymbol{c}} \\
\left(\boldsymbol{m} \boldsymbol{s}^{-\mathbf{1}}\right)\end{array}$ & $\begin{array}{c}\boldsymbol{E}_{w} \\
\left(\boldsymbol{m}^{2} \boldsymbol{s}\right)\end{array}$ & $\begin{array}{c}\boldsymbol{T}_{\boldsymbol{a}_{-} \text {avg }} \\
\left({ }^{\circ} \mathrm{C}\right)\end{array}$ & $\begin{array}{c}\boldsymbol{T}_{w_{-} a v g} \\
\left({ }^{\circ} \mathrm{C}\right)\end{array}$ & $\begin{array}{c}\boldsymbol{P}_{\text {frac }} \\
(\%)\end{array}$ \\
\hline $\mathbf{1}$ & $>4$ & & & & & & $\mathbf{1 6}$ \\
$\mathbf{2}$ & $>4$ & $>6$ & & & & & $\mathbf{2 8}$ \\
$\mathbf{3}$ & $>4$ & $>6$ & $>7$ & & & & $\mathbf{4 5}$ \\
$\mathbf{4}$ & $>4$ & $>6$ & $>7$ & $>0.1$ & & & $\mathbf{6 0}$ \\
$\mathbf{5}$ & $>4$ & $>6$ & $>7$ & $>0.1$ & $>5$ & & $\mathbf{7 5}$ \\
$\mathbf{6}$ & $>4$ & $>6$ & $>7$ & $>0.1$ & $>5$ & $>0$ & $>0$ & $\mathbf{7 5}$ \\
\hline
\end{tabular}

The fracture probability $\left(P_{\text {frac }}\right)$ for a given set of concurrent atmospheric and oceanic criteria sets were estimated using Eq. (3). To calculate the relative frequencies $P(Y \mid X)$ and $P(Y)$ in Eq. (3), the number of events from the fracture subset and all observations meeting the given criteria sets were identified and divided by the total number of observations in each subset. Considering criteria set $\mathrm{i}=2$ as an example, which accounts for only water temperature and wind speed, there are five events from the fracture subset and 18 events from all observations that have water temperature greater than $4{ }^{\circ} \mathrm{C}$ and wind speed greater than $6 \mathrm{~m} \mathrm{~s}^{-1}$. Given that the number of fracture events was 328 and the total number of observations was 17755, the relative frequency was estimated from Eq. (4) and integrated into Eq. (3) to calculate the conditional fracture probability for criteria set $\mathrm{i}=2$, given by:

$P\left(\right.$ Frac $\left.\mid T_{w}>4{ }^{\circ} \mathrm{C}, V_{w}>6 \mathrm{~m} \mathrm{~s}^{-1}\right)=\frac{P(\text { Frac }) P\left(T_{w}>4{ }^{\circ} \mathrm{C}, V_{w}>6 \mathrm{~m} \mathrm{~s}^{-1} \mid \mathrm{Frac}\right)}{P\left(T_{w}>4{ }^{\circ} \mathrm{C}, V_{w}>6 \mathrm{~m} \mathrm{~s}^{-1}\right)}=\frac{\frac{328}{17755} \times \frac{5}{328}}{\frac{18}{17755}} \approx 0.28$,

The calculated value in Eq. (5) indicates that if the conditions associated with the criteria set $\mathrm{i}=2$ hold, there is a $28 \%$ chance that these conditions lead the ice islands to fracture and split into two or more pieces. For each criteria set in Table 4, the same approach was employed to estimate the fracture probability as different conditions are added.

Table 4 has a predictive capability for the occurrence of fracture events for the Petermann ice islands under different atmospheric and oceanic conditional criteria sets. Some features of the criteria sets presented in Table 4 and their associated fracture event probability are noteworthy. An important implication of the results in Table 4 is the predominant link between the daily-average variables (i.e., $T_{w}, V_{w}, T_{a}, V_{c}$, and $E_{w}$ ) with the fracture event occurrence. When only the criteria for the air and water temperatures, wind and current speeds, and wave energy index are considered without accounting for the lifetime mean variables (criteria set $\mathrm{i}=5$ ), $75 \%$ of all events meeting these criteria occurred for the ice islands from the fracture subset. However, when only the high states of one or two variables are considered, the fracture probability drops to less than $30 \%$, which indicates the strong effect of concurrent atmospheric and oceanic conditions on the occurrence of ice island fracture events. Also, the criteria set $i=6$ in Table 4 reveals that, the addition of the lifetime mean variables did not increase the fracture probability above $75 \%$. This is due to the fact that the criteria set $\mathrm{i}=5$ narrowed down the atmospheric and oceanic conditions to a condition that already meets the criteria added in criteria set $\mathrm{i}=6$, implying that 
https://doi.org/10.5194/tc-2021-83

Preprint. Discussion started: 18 May 2021

(c) Author(s) 2021. CC BY 4.0 License.

(c) (i)

the conditions presented in criteria set $\mathrm{i}=5$ are enough to predict a fracture event probability up to $75 \%$. It is worth noting that the criteria sets represented in Table 4 implicitly account for the inter-relationship between the variables. For example, the criteria set $\mathrm{i}=3$, which considers high air and water temperatures, accounts for the correlation between air and water temperatures (Table 3), indicating that there is a high chance for the coincident occurrence of high air and water temperatures. It is also important to note that Table 4 only shows the criteria sets associated with the fracture events of ice islands originating from the calving events of the Petermann Glacier in 2008, 2010, 2011, and 2012. If more data become available from other fracture events of the Petermann ice islands, where the fracture events occur under different combinational criteria sets of atmospheric and oceanic conditions, then the variable ranges, the number of criteria sets, and the fracture probabilities presented in Table 4 would need to be updated.

The atmospheric and oceanic conditional criteria sets presented in Table 4 only show some specific criteria sets and clearly do not represent all possible combinations of the conditions. These criteria sets were selected by the progressive addition of one or two conditions to the previous criteria set, so that the associated conditional fracture probability would increase. However, to account for all possible conditions of the variables, the ranges for the atmospheric and oceanic variables were divided into two states using the methodology described earlier in Table 1. The elimination of current speed variable (as explained in the Sect. 2.3) reduced the number of state combinations from 128 to 64, which allowed for a greater number of occurrences for each combination of the states, with bin edges previously described in Table 1. Through an iterative process, the conditional fracture probability for each combination of the states was then calculated using Bayes Theorem (Eq. (3)). Due to the large number of elements (64 values) in the conditional probability table, it is not possible to illustrate all combinations of the variable states (Table 1) and their associated probability. So, the model description is limited to its qualitative part.

The results obtained from the presented Bayesian approach provide a framework to probabilistically forecast the future fracture events of ice islands originally calved from the Petermann Glacier. This probabilistic model can provide supplementary information to the available deterministic ice dynamic prediction models by quantifying the probability of ice island fracture event occurrence under various sets of concurrent atmospheric and oceanic conditions. To use this model, one needs to first identify the spatial and temporal coordinates of a given ice island and then extract or forecast the six dailyaverage and lifetime mean variables discussed earlier. Then, the obtained set of conditions is identified in the developed conditional probability table to quantify the associated probability of fracture event occurrence under the given set of atmospheric and oceanic conditions.

To better describe the utility of the developed fracture model, a case study was conducted on a descendant of ice islands resulting from the calving event of Petermann Glacier in 2010. This ice island was selected for a case study due to its drift characteristics. The ice island drifted for a long period (>7 months) and experienced a significant change in latitude $\left(>15^{\circ}\right)$. This ice island was born when its parent ice island broke into three pieces on 26 November 2010, and then fractured 405 later into two pieces on 5 July 2011. The spatial and temporal data for consecutive observations of this ice island were identified using the CI2D3 database. The atmospheric and oceanic variables were extracted from reanalysis databases and 
https://doi.org/10.5194/tc-2021-83

Preprint. Discussion started: 18 May 2021

(c) Author(s) 2021. CC BY 4.0 License.

(c) (i)

then interpolated to the positions and times of the given observations. The lifetime mean variables were also estimated using the methodology explained earlier, and the variables were all used as input to the presented fracture model to study the conditional fracture probabilities of the ice island over its drift path (Figure 6-a). To investigate the effect of different atmospheric and oceanic conditions on the fracture events of the same ice island, the metocean data during 2017-2018 were extracted and interpolated to the same positions as the case mentioned earlier, assuming that the time gaps between the observations are the same as the 2010-2011 case. Here it was assumed that the same drift trajectory applies, however, this would not likely be the case given that iceberg drift models are largely governed by the real-time metocean conditions (Lichey and Hellmer, 2001; Kubat et al., 2005; Eik, 2009; Keghouche et al., 2009; Rackow et al., 2017; Zeinali-Torbati et 415 al., 2020). This would be, however, an area for future work, where a drift model needs to be integrated into the proposed fracture model to have a reliable estimation of ice island positional data. The interpolated metocean data for the 2017-2018 case were then used in the presented fracture model to investigate how the fracture probability map would change under the influence of different atmospheric and oceanic conditions (Figure 6-b). The fracture probability map for the 2010-2011 case (Figure 6-a) reveals that the ice island drifted some time ( 14 days) in the medium-high fracture probability zone (shown by 420 the orange and red colors) before breaking up into two pieces. This, however, was not the case for the 2017-2018 ice island during the same time period (Figure 6-b) as this ice island only spent some time ( 14 days) in the small-medium fracture probability zone (shown by the green and orange colors) towards the end of its drift period off Labrador coast. The hypothetical 2017-2018 ice island, in fact, never experienced the metocean conditions that lead to a high probability of fracture events. This is likely due to the fact that the 2017-2018 ice island was generally exposed to lower water temperature ( $24 \%$ on average) over its drift. This result is expected given that water temperature was identified as the most important contributor to the fracture events of Petermann ice islands analyzed in this study. 
(a)

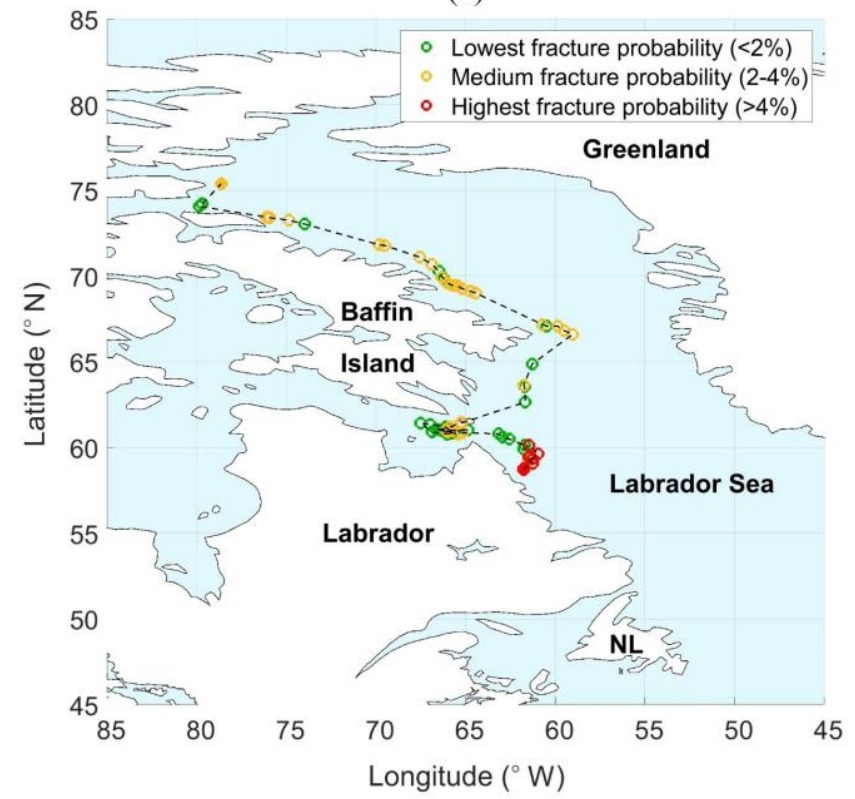

(b)

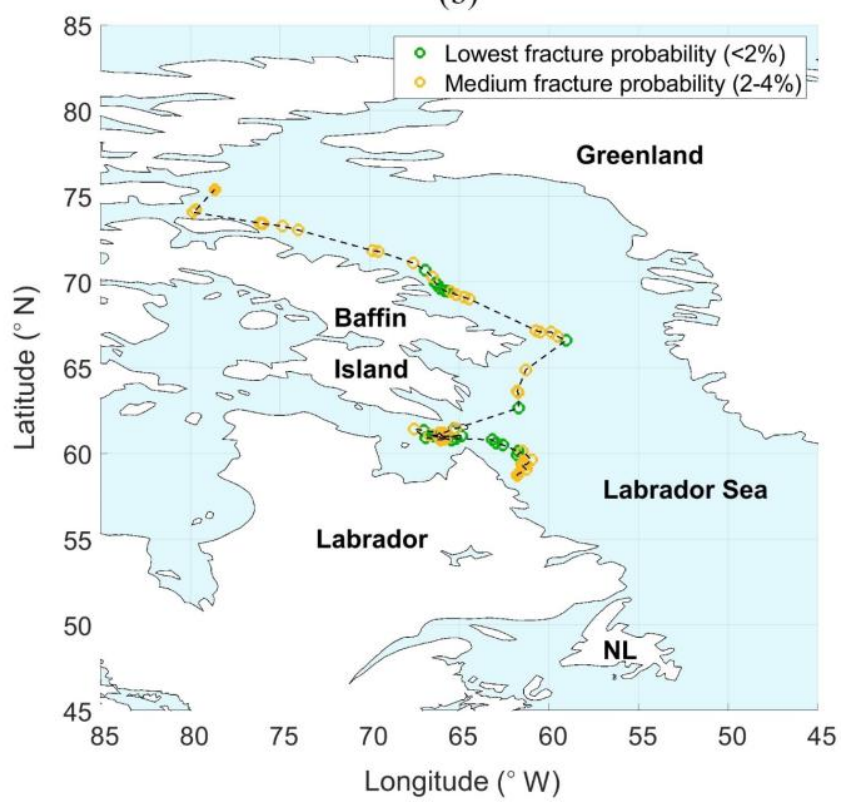

Figure 6. The fracture probability map for a descendant of the Petermann ice island from the 2010 calving event (a), compared against the projected fracture probabilities for the same ice island in 2017-2018 (b). The filled dots show the positions of the ice island at the time it was born and the time it fractured

While a Bayesian network has never been employed for forecasting ice island fracture events, the probabilistic model presented in this paper was developed based on the methodology used in Turnbull et al. (2019) and Fu et al. (2016), where the Bayesian approach was used to predict vessel besetting events in pack ice. The study by Fu et al. (2016) used a Bayesian network to investigate the inter-relationship between nine variables (i.e., ship speed, engine power, wind speed, air temperature, low visibility, sea temperature, ice concentration, ice thickness, and wave height), as well as their influence on the probability of a ship getting stuck in ice while navigating through the Northern Sea Route. Using a similar Bayesian approach, Turnbull et al. (2019) studied two pack ice besetting events of the Umiak I and developed a probabilistic forecast model for future besetting events experienced by Umiak I under the influence of nine ice and metocean variables (i.e., ice concentration, ice thickness, floe size, minimum coast distance, wind-coast direction, wind speed, current-coast direction, current speed, and wind divergence). While this approach has not been used in a past iceberg fracture model, there are some deterioration models such as the one by Kubat et al. (2007) that account for the influence of metocean variables (e.g., wind speed, current speed, water temperature, wave height, and wave period) on the calving events of the overhanging slabs resulting from the repeated action of waves. Kubat et al. (2007) revealed that wave height and water temperature dominate effects on iceberg deterioration through melt and small-scale wave-induced calving events. However, the probabilistic model presented here accounts for the large-scale fracture events in ice islands under the influence of various metocean conditions that govern the occurrence of these events. To date, no probabilistic or deterministic models have been presented to 
investigate the atmospheric and oceanic conditions that lead to the highest probability of large-scale fracture event occurrence for ice islands. Therefore, it is impossible to compare the methodologies and results of the presented Bayesian fracture model with an existing physical ice island fracture model. Hence, the presented model was validated using a wellknown scheme in probabilistic data analysis studies, which is described in Sect. 4.

\section{Probabilistic model validation}

The developed probabilistic model was validated using a resampling approach. The results presented earlier were developed using all fracture event data from the Petermann ice islands; however, the Pareto principle (Macek, 2008) suggests $80 \%$ of the data be used for model training and development, and $20 \%$ be reserved for testing the developed model (Suthaharan, 2016). To reduce the effect of variation in the subset selection and have a more robust evaluation of the developed model, a k-fold cross-validation approach (Ozdemir, 2016) was used $(\mathrm{k}=5)$. So, input variables associated with the fracture and non-fracture data were randomly partitioned into five disjoint subsets of approximately equal size, where each time one of these subsets served for model testing, and the rest were used to train the model. This corresponded to the selection of training subsets with approximately 14205 data points (262 fracture events and 13943 non-fracture events) and test subsets with approximately 3550 data points (66 fracture events and 3484 non-fracture events). The conditional fracture probabilities of ice islands for the given criteria sets were calculated using the atmospheric and oceanic conditions for each test subset and then cross-validated against the predicted values associated with its corresponding training set (Table 5).

Table 5. Model validation for some of the criteria sets in the model (e.g., criteria set $\mathrm{i}=5$ shows one of the 64 state combinations of the six variables; criteria set $\mathrm{i}=4$ represents one of the 16 state combinations of the four variables). The variables included water temperature $\left(T_{w}\right)$, wind speed $\left(V_{w}\right)$, air temperature $\left(T_{a}\right)$, wave energy index $\left(E_{w}\right)$, lifetime mean air temperature $\left(T_{a_{-} a v g}\right)$, and lifetime mean water temperature $\left(T_{w_{-} a v g}\right)$. Model error is derived through statistical comparison of fracture probability estimations from training sets and test sets, obtained using 5-fold cross-validation method

\begin{tabular}{|c|c|c|c|c|c|c|c|c|c|c|c|c|}
\hline \multirow{2}{*}{$\begin{array}{c}\text { Criteria } \\
\text { Set } \mathbf{i}\end{array}$} & \multirow{2}{*}{$\begin{array}{l}T_{w} \\
\left({ }^{\circ} \mathrm{C}\right)\end{array}$} & \multirow{2}{*}{$\begin{array}{c}V_{w} \\
\left(m s^{-1}\right)\end{array}$} & \multirow{2}{*}{$\begin{array}{c}T_{a} \\
\left({ }^{\circ} \mathrm{C}\right)\end{array}$} & \multirow{2}{*}{$\begin{array}{c}E_{w} \\
\left(m^{2} s\right)\end{array}$} & \multirow{2}{*}{$\begin{array}{c}T_{a \_a v g} \\
\left({ }^{\circ} \mathrm{C}\right)\end{array}$} & \multirow{2}{*}{$\begin{array}{c}T_{w_{-} a v g} \\
\left({ }^{\circ} \mathrm{C}\right)\end{array}$} & \multicolumn{2}{|c|}{$P_{\text {frac_training }}(\%)$} & \multicolumn{2}{|c|}{$P_{\text {frac_test }}{ }^{1}(\%)$} & \multirow{2}{*}{\begin{tabular}{|c|} 
Pairwise $\%$ Error \\
Test vs. Training
\end{tabular}} & \multirow{2}{*}{$\begin{array}{c}\boldsymbol{P}_{\text {frac_all }} \\
(\%)\end{array}$} \\
\hline & & & & & & & Mean & Std. $^{3}$ & Mean & Std. $^{3}$ & & \\
\hline 1 & $>-0.5$ & & & & & & 3.3 & 0.1 & 3.4 & 0.4 & 13 & 3.3 \\
\hline 2 & $>-0.5$ & $>2.8$ & & & & & 3.4 & 0.2 & 3.5 & 0.9 & 20 & 3.5 \\
\hline 3 & $>-0.5$ & $>2.8$ & $>-2.1$ & & & & 3.8 & 0.3 & 3.8 & 1.2 & 24 & 3.8 \\
\hline 4 & $>-0.5$ & $>2.8$ & $>-2.1$ & $>5.1$ & & & 6.1 & 0.6 & 6.0 & 2.4 & 33 & 6.2 \\
\hline 5 & $>-0.5$ & $>2.8$ & $>-2.1$ & $>5.1$ & $>-3.5$ & $>-0.7$ & 6.5 & 0.9 & 6.6 & 3.4 & 39 & 6.7 \\
\hline
\end{tabular}

${ }^{1} P_{\text {frac_training }}, P_{\text {frac_test }}$, and $P_{\text {frac_all }}$ represent the fracture probability estimations from the training subsets, test subsets, and all data points, respectively

$470{ }^{2}$ Absolute error between the fracture probability estimations from the training and test subsets

${ }^{3}$ Standard deviation

The results of the fracture model validation analysis for the selected criteria sets (Table 5) reveal that the mean 
https://doi.org/10.5194/tc-2021-83

Preprint. Discussion started: 18 May 2021

(c) Author(s) 2021. CC BY 4.0 License.

(c) (i)

fractures probabilities estimated from the test subsets are in agreement with the mean estimations from the training subsets as the ranges for the fracture probability values overlap. Investigation of the errors between the pairwise (test vs. training) fracture probability values show that the test sets selected using the 5-fold cross-validation approach are able to provide estimations that are, on average, within 13-39\% of the values forecasted using the training sets. It was also revealed from the standard deviation values that the presented model is more reliable when a fewer number of variables or state combinations are considered (e.g., criteria set $\mathrm{i}=1$ ). This is because, as the number of variables or state combinations increase, there are fewer fracture events and the ranges of atmospheric and oceanic conditions become more constrained, so the number of events meeting these given criteria decreases. With fewer observations, there will be more variability and consequently a higher error in the predicted fracture probability values. If more fracture data in each criteria set become available, the model will become more robust and the error in fracture probability estimations is expected to reduce.

The 5 -fold cross-validation analysis presented in Table 5 only shows some of the possible combinations of variable states. This corresponds to $1 / 2$ one-variable combinations ( $\mathrm{i}=1$ ), $1 / 4$ two-variable combinations ( $\mathrm{i}=2$ ), 1/8 three-variable combinations ( $\mathrm{i}=3$ ), 1/16 four-variable combinations ( $\mathrm{i}=4$ ), and 1/64 six-variable combinations ( $\mathrm{i}=6$ ). However, the model skill was also analyzed for the remaining combinations, and it was revealed that the model does not perform well under implausible combinations of the atmospheric and oceanic conditions, which are not likely to be encountered and do not hinder the model most of the time. For example, based on the extracted/interpolated metocean data for the full model with all six variables, 36 combinations (out of 64) never occurred, so the fracture probabilities under such conditions are unknown. However, the remaining 28 combinations that were met revealed a larger error ( 100-200\%) between the probability estimations from the training and test subsets, when the associated combination was unlikely to occur $(<1 \%)$. For instance, due to the very few data points existing for these improbable combinations, there were some cases that were not observed in the test subsets but were observed only a few times in the training subsets, which inflated an error of $100 \%$. However, our model showed higher reliability under plausible combination of metocean conditions, such as the criteria sets $\mathrm{i}=1-5$ in Table 5 (13-39\% error), or when fewer number of variables were used in the model that generated much less error between the probability estimations from the test and training subsets (e.g., 11-97\% for 1-4 variables).

\section{Conclusions and future work}

This study presented a probabilistic forecast model for the fracture events of ice islands through the analysis of the relative influences of atmospheric and oceanic forces. The recurrent deterioration of the ice islands originating from four recent calving events of Petermann Glacier were studied using the data in the CI2D3 database to probabilistically investigate the conditions that lead to fracture event occurrence of the ice islands. It was revealed in Figure 3 through Figure 5 that while fracture events generally occurred when the ice islands were subjected to more severe atmospheric and oceanic conditions (e.g., high wind and current speed, air and water temperature, wave energy index, and lifetime mean air and water temperature), warm water temperature played the most important role in the large-scale fracture events of Petermann ice islands. The results also showed that ice islands subjected to high values of daily-average metocean variables (as specified in 
https://doi.org/10.5194/tc-2021-83

Preprint. Discussion started: 18 May 2021

(c) Author(s) 2021. CC BY 4.0 License.

(c) (i)

Table 4), are expected to have a 75\% chance of fracturing. The model validation was performed using k-fold cross-validation approach based on the Pareto principle, and it was found that the error between the estimated fracture probabilities from training and test sets ranged from $13 \%$ when only water temperature criterion is considered, to $39 \%$ for the full set of criteria.

The results of this study provide an important step toward the development of a probabilistic forecast model for fracture events of ice islands. The model presented here was built on the fracture event data associated with the ice islands that originated from Petermann Glacier, and therefore applies only to specific ice islands which share similar ice strength properties. Ice islands from other glaciers may have higher or lower ice strength characteristics and could experience fracture events under narrower or wider ranges of metocean conditions than presented in this study. The atmospheric and oceanic conditions, and their corresponding fracture event probabilities presented in Table 4 and Table 5 need to be updated if more deterioration data become available to improve the model accuracy. The atmospheric and oceanic conditions in the presented model were extracted from reanalysis datasets; however, for the presented model to have an operational forecast use, the metocean conditions and fracture event probabilities should be estimated using the inputs from deterministic models that have the ability to provide short-term forecasts. The results of this study can be used with a limited number of variables. For example, in case only daily-average wind and air/water temperature data for the ice islands are available, the model should be restricted to criteria sets $\mathrm{i}=1-3$. Once more variable data become available (e.g., wave and lifetime mean variables), then the probabilistic fracture event estimations may take into account the expanded criteria sets (e.g., i=4-5).

Future work should focus on improving this model through expanding the deterioration database of Petermann ice islands, as well as evaluating the fracture event data associated with other ice islands. The presented model was developed based on the data from 328 fracture events; however, more data are needed to train and test this model. The probabilistic model presented here only considered two states for each variable to avoid model saturation given the limited number of data points. If more data become available, one can improve the model resolution by using a greater number of variable states (e.g., three or four). While this study used seven input variables to develop a probabilistic fracture model, future research can also investigate the role of other variables such as sea ice concentration/thickness and ice island size on fracture events of ice islands. Also, the incorporation of in-situ measured metocean data can contribute significantly to further validation of the presented ice island fracture model. Finally, for this model to have a forecast capability for future ice island fracture events, the presented fracture model needs to be coupled with a drift model able to reliably forecast the positional data. A probabilistic drift model for the Petermann ice islands in the CI2D3 database is currently under development by the same authors, which will then be integrated into the presented fracture model to ultimately present a coupled ice island drift and deterioration forecast model.

The research presented here fills some of the critical knowledge gaps in glacial ice deterioration forecasts. The results of this study provide an important step in characterizing the atmospheric and oceanic conditions that govern the largescale fracture events of ice islands, which are important for improving the calibration of operational ice dynamics models. The increase in the air and water temperatures due to the climate change is expected to drive more frequent massive calving 
https://doi.org/10.5194/tc-2021-83

Preprint. Discussion started: 18 May 2021

(c) Author(s) 2021. CC BY 4.0 License.

(c) (i)

540 events of Petermann Glacier in the future (Münchow et al., 2016), which could lead to the generation of numerous drifting ice islands off the east coast of Canada. The ability to predict fracture events of these ice islands could contribute to the development of more reliable strategies to mitigate the risks associated with the presence of glacial ice features, which is necessary for supporting safe offshore operations and marine activities in the ice-prone waters off the east coast of Canada.

Data availability. The CI2D3 database and its documentation can be accessed at http://dx.doi.org/10.21963/12678.

545 Author contributions. IT and RT assisted in the acquisition of the financial support for this study. RZ carried out the reanalysis and CI2D3 data extraction/interpolation with assistance from IT and DM, respectively. RZ developed the methodology with guidance from IT and RT, and analyzed data, developed the model, and prepared the manuscript, with critical review, feedback, and commentary from IT, RT, and DM.

Competing interests. The authors declare that they have no conflict of interest.

550 Acknowledgements. The CI2D3 database used in this study was originally developed through a collaboration between the Water and Ice Research Lab (WIRL) at Carleton University and the Canadian Ice Service (CIS). We thank the team of researchers at WIRL, NARR, CMEMS, and ECMWF who provided the database and reanalysis data for this study. We also acknowledge the CIS for providing the digital daily ice charts analyzed in this study. Financial support from Hibernia Management and Development Company (HMDC), MITACS Accelerate Program, and the School of Graduate Studies at 555 Memorial University of Newfoundland is gratefully acknowledged.

\section{References}

Akpınar, A., Jafali, H., and Rusu, E.: Temporal variation of the wave energy flux in hotspot areas of the black sea, Sustainability, 11(3), 562, https://doi.org/10.3390/su11030562, 2019.

Bahr, D. B.: Simulating iceberg calving with a percolation model. J. Geophys. Res.: Solid Earth, 100(B4), 6225-6232, https://doi.org/10.1029/94JB03133, 1995.

Ballicater Consulting Ltd.: Ice Island and Iceberg Studies 2012, Report prepared for the Canadian Ice Service, Environment Canada, Report 12-01 (51 pp.), 2012.

Bassis, J. N. and Jacobs, S.: Diverse calving patterns linked to glacier geometry, Nat. Geosci., 6(10), 833-836, https://doi.org/10.1038/ngeo1887, 2013.

565 Bonafede, C. E. and Giudici, P.: Bayesian networks for enterprise risk assessment, Physica A, 382(1), 22-28, https://doi.org/10.1016/j.physa.2007.02.065, 2007.

Christakos, K., Varlas, G., Cheliotis, I., Spyrou, C., Aarnes, O. J., and Furevik, B. R.: Characterization of wind-sea-and swell-induced wave energy along the Norwegian coast, Atmosphere, 11(2), 166, https://doi.org/10.3390/atmos11020166, 2020. 
https://doi.org/10.5194/tc-2021-83

Preprint. Discussion started: 18 May 2021

(c) Author(s) 2021. CC BY 4.0 License.

(c) (i)

Crawford, A. J.: Ice island deterioration, PhD Dissertation, Department of Geography and Environmental Studies, Carleton University, Ottawa, Canada, https://doi.org/10.22215/etd/2018-13178, 2018.

Crawford, A. J., Mueller, D. R., Humphreys, E. R., Carrieres, T., and Tran, H.: Surface ablation model evaluation on a drifting ice island in the Canadian Arctic, Cold Reg. Sci. Technol., 110, 170-182, https://doi.org/10.1016/j.coldregions.2014.11.011, 2015.

Crawford, A. J., Wadhams, P., Wagner, T. J., Stern, A., Abrahamsen, E. P., Church, I., Bates, R., and Nicholls, K. W.: Journey of an Arctic ice island, Oceanography, 29(2), 254-263, https://doi.org/10.5670/oceanog.2016.30, 2016.

Crawford, A. J., Crocker, G., Mueller, D., Desjardins, L., Saper, R., and Carrieres, T.: The Canadian ice island drift, deterioration and detection (CI2D3) database, J. Glaciol., 1-5, https://doi.org/10.1017/jog.2018.36, 2018a.

Crawford, A. J., Desjardins, L., Saper, R., Mueller, D., Stewart-Jones, E.: Canadian ice island drift, deterioration and detection (CI2D3) database documentation [v1.1], Water and Ice Research Laboratory, Carleton University, Ottawa, 19 pp., 2018 b.

Crawford, A. J., Mueller, D., and Joyal, G.: Surveying drifting icebergs and ice islands: deterioration detection and mass estimation with aerial photogrammetry and laser scanning, Remote Sens., 10(4), 575, https://doi.org/10.3390/rs10040575, 2018c.

585 Crawford, A. J., Mueller, D., Desjardins, L., and Myers, P. G.: The aftermath of Petermann glacier calving events (20082012): ice island size distributions and meltwater dispersal, J. Geophys. Res.: Oceans, 123(12), 8812-8827, https://doi.org/10.1029/2018JC014388, 2018d.

Crawford, A. J., Mueller, D., Crocker, G., Mingo, L., Desjardins, L., Dumont, D., and Babin, M.: Ice island thinning: rates and model calibration with in-situ observations from Baffin Bay, Nunavut, The Cryosphere, 14, 1067-1081, https://doi.org/10.5194/tc-14-1067-2020, 2020.

Crocker, G., Carrieres, T., and Tran, H.: Ice island drift and deterioration forecasting in eastern Canada. In Proceedings of the 22nd International Conference on Port and Ocean Engineering Under Arctic Conditions, Espoo, Finland, 9-13 June 2013, 2013.

Desjardins, L., Crawford, A., Mueller, D., Saper, R., Schaad, C., Stewart-Jones, E., and Shepherd, J.: Canadian ice island drift, deterioration and detection database (CI2D3 database) [v1.1], Canadian Cryospheric Information Network (CCIN), Waterloo, Canada, http://dx.doi.org/10.21963/12678, 2018.

Eik, K.: Iceberg drift modelling and validation of applied metocean hindcast data. Cold Reg. Sci. Technol., 57(2-3), 67-90, https://doi.org/10.1016/j.coldregions.2009.02.009, 2009.

Eleye-Datubo, A. G., Wall, A., Saajedi, A., and Wang, J.: Enabling a powerful marine and offshore decision-support 
https://doi.org/10.5194/tc-2021-83

Preprint. Discussion started: 18 May 2021

(c) Author(s) 2021. CC BY 4.0 License.

(c)

solution through Bayesian network technique, Risk Anal., 26(3), 695-721, https://doi.org/10.1111/j.15396924.2006.00775.x, 2006.

El-Tahan, M., Venkatesh, S., and El-Tahan, H.: Validation and quantitative assessment of the deterioration mechanisms of Arctic icebergs, J. Offshore Mech. Arct. Eng., 109(1), 102-108, https://doi.org/10.1115/1.3256983, 1987.

Enderlin, E. M., Hamilton, G. S., Straneo, F., and Sutherland, D. A.: Iceberg meltwater fluxes dominate the freshwater budget in Greenland's iceberg-congested glacial fjords, Geophys. Res. Lett., 43(21), 11-287, https://doi.org/10.1002/2016GL070718, 2016.

Erickson, T. R. and Stefan, H. G.: Linear air/water temperature correlations for streams during open water periods, J. Hydrol. Eng., 5(3), 317-321, http://dx.doi.org/10.1061/(ASCE)1084-0699(2000)5:3(317), 2000.

Falnes, J.: A review of wave-energy extraction, Mar. struct., 20(4), 185-201, https://doi.org/10.1016/j.marstruc.2007.09.001, 2007.

Freedman, D. A.: Statistical models and causal inference: a dialogue with the social sciences, Cambridge University Press, https://doi.org/10.1017/CBO9780511815874, 2010.

Fu, S., Zhang, D., Montewka, J., Yan, X., and Zio, E.: Towards a probabilistic model for predicting ship besetting in ice in Arctic waters, Reliab. Eng. Syst. Saf., 155, 124-136, https://doi.org/10.1016/j.ress.2016.06.010, 2016.

615 Fuglem M., Jordaan I.: Risk analysis and hazards of ice islands, In: Copland L., Mueller D. (eds) Arctic Ice Shelves and Ice Islands, Springer Polar Sciences, Springer, Dordrecht, https://doi.org/10.1007/978-94-024-1101-0_15, 2017.

Gutierrez, B. T., Plant, N. G., and Thieler, E. R.: A Bayesian network to predict coastal vulnerability to sea level rise, J. Geophys. Res.: Earth Surf., 116(F2), https://doi.org/10.1029/2010JF001891, 2011.

Halliday, E. J., King, T., Bobby, P., Copland, L., and Mueller, D. R.: Petermann ice island 'A' survey results, offshore Labrador, in: Proceedings of the Arctic Technology Conference, Houston, Texas, USA, 3-5 December 2012, OTC 23714, https://doi.org/10.4043/23714-MS, 2012.

Hock, R.: Temperature index melt modeling in mountain areas, J. Hydrol., 282, 104-115, https://doi.org/10.1016/S00221694(03)00257-9, 2003.

Jeffries, M. O.: Ellesmere Island ice shelves and ice islands, Satellite Image Atlas of Glaciers of the World: Glaciers of North America - Glaciers of Canada, J147-J164, 2002.

Job, J. G.: Numerical modelling of iceberg towing for water supplies-A case study, J. Glaciol., 20(84), 533-542, https://doi.org/10.3189/S002214300002092X, 1978.

Johannessen, O. M., Babiker, M., and Miles, M. W.: Petermann Glacier, North Greenland: massive calving in 2010 and the 
https://doi.org/10.5194/tc-2021-83

Preprint. Discussion started: 18 May 2021

(c) Author(s) 2021. CC BY 4.0 License.

(c)

past half century, The Cryosphere Discussions, 5(1), 169-181, https://doi.org/10.5194/tcd-5-169-2011, 2011.

630 Keghouche, I., Bertino, L., and Lisæter, K. A.: Parameterization of an iceberg drift model in the Barents Sea, J. Atmos. Oceanic Technol., 26(10), 2216-2227, https://doi.org/10.1175/2009JTECHO678.1, 2009.

Kubat, I., Sayed, M., Savage, S. B., and Carrieres, T.: An operational model of iceberg drift, Int. J. Offshore Polar Eng., 15(2), 125-131, 2005.

Kubat, I., Sayed, M., Savage, S.B., Carrieres, T., and Crocker, G.: An operational iceberg deterioration model, Proceedings of the 17th International Offshore and Polar Engineering Conference, Lisbon, Portugal, 1-6 July 2007, 652-657, 2007.

Lichey, C. and Hellmer, H. H.: Modeling giant-iceberg drift under the influence of sea ice in the Weddell Sea, Antarctica, J. Glaciol., 47(158), 452-460, https://doi.org/10.3189/172756501781832133, 2001.

Macek, K.: Pareto principle in datamining: an above-average fencing algorithm, Acta Polytech., 48(6), 55-59, 640 https://doi.org/10.14311/1075, 2008.

Merino, N., Le Sommer, J., Durand, G., Jourdain, N. C., Madec, G., Mathiot, P., and Tournadre, J.: Antarctic icebergs melt over the Southern Ocean: Climatology and impact on sea ice, Ocean Modell., 104, 99-110, https://doi.org/10.1016/j.ocemod.2016.05.001, 2016.

Montewka, J., Sinclair, H., Kujala, P., Haapala, J., and Lensu, M.: Modelling ship performance in ice using Bayesian networks, In Proceedings of the $22^{\text {nd }}$ international conference on port and ocean engineering under Arctic conditions, June 9-13 2013, 2013.

Montewka, J., Goerlandt, F., Kujala, P., and Lensu, M.: Towards probabilistic models for the prediction of a ship performance in dynamic ice, Cold Reg. Sci. Technol., 112, 14-28, https://doi.org/10.1016/j.coldregions.2014.12.009, 2015.

650 Morrill, J. C., Bales, R. C., and Conklin, M. H.: The relationship between air temperature and stream temperature, In AGU Spring Meeting Abstracts, 2001, H42A-09, 2001.

Mueller, D.R., Crawford, A., Copland, L., and Van Wychen, W.: Ice island and iceberg fluxes from Canadian High Arctic sources, Report to the Northern Transportation Assessment Initiative (23 pp.), Innovation Policy Branch, Transport Canada, Ottawa, Canada, 2013.

655 Münchow, A., Padman, L., Washam, P., and Nicholls, K. W.: The ice shelf of Petermann Gletscher, North Greenland, and its connection to the Arctic and Atlantic Oceans, Oceanography, 29(4), 84-95, https://doi.org/10.5670/oceanog.2016.101, 2016.

Nick, F. M., Luckman, A., Vieli, A., Van der Veen, C. J., Van As, D., Van De Wal, R. S. W., Pattyn, F., Hubbard, A. L., and 
https://doi.org/10.5194/tc-2021-83

Preprint. Discussion started: 18 May 2021

(c) Author(s) 2021. CC BY 4.0 License.

(c) (i)

660

Floricioiu, D.: The response of Petermann Glacier, Greenland, to large calving events, and its future stability in the context of atmospheric and oceanic warming, J. Glaciol., 58(208), 229-239, https://doi.org/10.3189/2012JoG11J242, 2012.

Ozdemir, S.: Principles of Data Science (1st ed.), Packt Publishing, 2016.

Peterson, I. K.: Ice island occurrence on the Canadian East Coast, In Proceedings of the 21st International Conference on Port and Ocean Engineering under Arctic Conditions, POAC11-044, Montreal, Canada, 10-14 July 2011, 2011.

665 Rackow, T., Wesche, C., Timmermann, R., Hellmer, H. H., Juricke, S., and Jung, T.: A simulation of small to giant Antarctic iceberg evolution: Differential impact on climatology estimates, J. Geophys. Res.: Oceans, 122(4), 3170-3190, https://doi.org/10.1002/2016JC012513, 2017.

Saper, R.: Preliminary research plan for glacial ice hazards (40 pp.). Report prepared for the Canadian Ice Service, Marine and Ice Services Division, Environment Canada, Ottawa, Canada, 2011.

670 Savage, S. B.: Aspects of iceberg deterioration and drift, In Geomorphological Fluid Mechanics, Springer, Berlin, Germany, 589, 279-318, https://doi.org/10.1007/3-540-45670-8_12, 2001.

Smith, J.: Modelling ice island calving events with Finite Element Analysis, Master's Thesis, Department of Geography and Environmental Studies, Carleton University, Ottawa, Canada, https://doi.org/10.22215/etd/2020-13905, 2020.

Stern, A. A., Johnson, E., Holland, D. M., Wagner, T. J., Wadhams, P., Bates, R., Abrahamsen E. P., Nicholls, K. W., Crawford A., Gagnon, J., and Tremblay, J. E.: Wind-driven upwelling around grounded tabular icebergs, J. Geophys. Res.: Oceans, 120(8), 5820-5835, https://doi.org/10.1002/2015JC010805, 2015.

Stern, A. A., Adcroft, A., and Sergienko, O., The effects of Antarctic iceberg calving-size distribution in a global climate model, J. Geophys. Res.: Oceans, 121(8), 5773-5788, https://doi.org/10.1002/2016JC011835, 2016.

Stern, A. A., Adcroft, A., Sergienko, O., and Marques, G., Modeling tabular icebergs submerged in the ocean, J. Adv. Model. Earth Syst., 9(4), 1948-1972, https://doi.org/10.1002/2017MS001002, 2017.

Stuart, A. and Ord, K.: Kendall's Advanced Theory of Statistics, Volume 1: Distribution Theory, 6th Edition, Edward Arnold, London, 1994.

Suthaharan, S.: Machine learning models and algorithms for big data classification, Integrated Series in Information Systems, 36, 1-12, https://doi.org/10.1007/978-1-4899-7641-3, 2016.

685 Tournadre, J., Bouhier, N., Girard-Ardhuin, F., and Rémy, F.: Antarctic icebergs distributions 1992-2014, J. Geophys. Res.: Oceans, 121(1), 327-349, https://doi.org/10.1002/2015JC011178, 2016.

Turnbull, I. D., Bourbonnais, P., and Taylor, R. S.: Investigation of two pack ice besetting events on the Umiak I and 
https://doi.org/10.5194/tc-2021-83

Preprint. Discussion started: 18 May 2021

(c) Author(s) 2021. CC BY 4.0 License.

(c) (i)

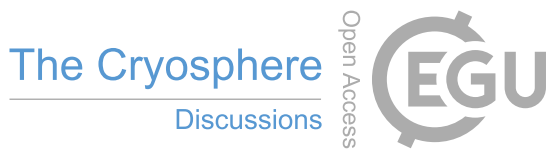

development of a probabilistic prediction model, Ocean Eng., 179, 76-91, https://doi.org/10.1016/j.oceaneng.2019.03.030, 2019.

690 Wagner, T. J., Wadhams, P., Bates, R., Elosegui, P., Stern, A., Vella, D., Abrahamsen, E. P., Crawford, A., and Nicholls, K. W.: The "footloose" mechanism: Iceberg decay from hydrostatic stresses, Geophys. Res. Lett., 41(15), 5522-5529, https://doi.org/10.1002/2014GL060832, 2014.

Wagner, T. J., Dell, R. W., and Eisenman, I.: An analytical model of iceberg drift, J. Phys. Oceanogr., 47(7), 1605-1616, https://doi.org/10.1175/JPO-D-16-0262.1, 2017.

695 Waters, R.: Energy from ocean waves: full scale experimental verification of a wave energy converter, Doctoral dissertation, Uppsala University, Sweden, 2008.

White, F. M., Spaulding, M. L., and Gominho, L.: Theoretical estimates of the various mechanisms involved in iceberg deterioration in the open ocean environment, U.S. Coast Guard Research and Development Center Report, p. 126, 1980.

700 Zeinali-Torbati, R., Turnbull, I. D., Taylor, R. S., and Mueller, D.: The calving events of Petermann glacier from 2008 to 2012: ice island drift characteristics, assessment of fracture events, and geographical data analysis. In proceedings of the 38th International Conference on Ocean, Offshore and Arctic Engineering, Glasgow, Scotland, UK, https://doi.org/10.1115/OMAE2019-96732, 9-14 June 2019, 2019.

Zeinali-Torbati, R., Turnbull, I. D., Taylor, R. S., and Mueller, D.: Evaluation of the relative contribution of meteorological 705 and oceanic forces to the drift of ice islands offshore Newfoundland, J. Glaciol., 66(256), 203-218, https://doi.org/10.1017/jog.2019.96, 2020.

Zhang, D., Yan, X. P., Yang, Z. L., Wall, A., and Wang, J.: Incorporation of formal safety assessment and Bayesian network in navigational risk estimation of the Yangtze River, Reliab. Eng. Syst. Saf., 118, 93-105, https://doi.org/10.1016/j.ress.2013.04.006, 2013. 